\title{
Yüksek Teknoloji Ürün İhracatının Gelir Üzerine Etkisi: Translog Üretim Fonksiyonuna Dair Bulgular*
}

\section{The Impact of High-Tech Exports on Income: Findings on the Translog Production Function}

\author{
Devran ŞANLI ${ }^{1}$, Aziz KONUKMAN ${ }^{2}$ (])
}

\section{Öz}

Bu çalışmanın amacı, yüksek teknoloji(HT) ihracatın gelir üzerindeki etkisini panel veri yöntemleriyle 49 ülke ve 1988-2017 dönemi için hem Cobb-Dougles hem de Translog üretim fonksiyonu altında analiz ederek literatüre yeni bulgular sunmaktır. Translog üretim fonksiyonunda HT-Gelir ilişkisini araştıran başka bir çalışmaya rastlanılmamıştır. Bu yönüyle mevcut analiz öncül bir çalışma özelliği taşımaktadır. Referans modelde SEK varsayımlarının karşılanamaması nedeniyle söz konusu problemlerin varlığında dirençli standart hatalar üreten Driscoll-Kraay yöntemiyle regresyon katsayıları tahmin edilmiştir. Ayrıca, seriler arasında eşbütünleşmenin varlığı artıkların durağanlığı ile araştırımıştır. Elde edilen bulgulara göre, fiziki sermayenin ölçeğe katkısı olan gelir esnekliği 0,668; beşeri sermayenin gelir esnekliği 0,584 ve HT ihracatının gelir esnekliği 0,071 düzeyinde hesaplanmıştır. Bununla birlikte, HT ihracatının işgücü başına gelire azalarak artan, beşeri sermayenin ise işgücü başına gelire ise artarak artan bir eğri boyunca katkı verdiği tespit edilmiştir. Fiziki sermaye ve gelir ilişkisinin ise doğrusal olduğu görülmektedir. Bu bulgular ana modellere ek olarak alternatif regresyon yöntemleriyle sağlamlık kontrolünden geçirilmiş ve mevcut modellerle uyumlu neticeler elde edilmiştir.

Anahtar kelimeler: Yüksek teknoloji ihracatı, Translog, Gelir JEL Sınıflaması: E23, F14, C33

\section{ABSTRACT}

This study aims to present new findings to the literature by analyzing the impact of high-tech(HT) exports on revenue using panel data methods in 49 countries and under both CobbDouglas and Translog production functions for the period 19882017. No other study has been found in the literature investigating the HT-Income relationship in the Translog production function. In this aspect, the current analysis is a pioneer study. Regression coefficients were estimated by the Driscoll-Kraay method, which produces robust standard errors in cases where OLS assumptions cannot be met. Furthermore, the existence of cointegration between the series was investigated by the stationarity of the residuals. According to the findings, the income elasticity of the
\end{abstract}

\begin{abstract}
* Bu çalışma, birinci yazarın ikinci yazar danışmanlığında tamamlanan doktora tezinden türetilmiştir.
\end{abstract}

${ }^{1}$ Dr., Bartın Üniversitesi, İktisadi ve İdari Bilimler Fakültesi, İktisat Bölümü, Bartın, Türkiye

2Prof. Dr., Ankara Hacı Bayram Veli Üniversitesi, İktisadi ve İdari Bilimler Fakültesi, İktisat Bölümü, Ankara, Türkiye

ORCID: D.Ş. 0000-0003-4106-3799; A.K. 0000-0003-0269-3245

Sorumlu yazar/Corresponding author: Devran ŞANLI,

Bartın Üniversitesi, İktisadi ve İdari Bilimler Fakültesi, Iktisat Bölümü, Bartın, Türkiye E-posta/E-mail: devransanli@gmail.com

Başvuru/Submitted: 24.07.2021

Revizyon Talebi/Revision Requested: 21.09.2021

Son Revizyon/Last Revision Received: 26.09.2021

Kabul/Accepted: 21.12 .2021

Atıf/Citation: Sanli, D., \& Konukman, A. (2021). Yüksek teknoloji ürün ihracatının gelir üzerine etkisi: Translog üretim fonksiyonuna dair bulgular. İstanbul Iktisat Dergisi - Istanbul Journal of Economics, 71(2), 457-498. https://doi.org/10.26650/ISTJECON2021-974011 
physical capital contributing to the scale is 0.668 ; income elasticity of human capital was calculated as 0.584 and income elasticity of HT exports was calculated as 0.071 . However, HT exports have been found to contribute to income per labor force, while human capital contributes to income per labor force along an increasing curve. The relationship between physical capital and income seems decidedly linear. These findings were tested for robustness with alternative regression methods in addition to the main models, and results compatible with the existing models were obtained.

Keywords: High-tech exports, Translog, Income JEL Classification: E23, F14, C33

\section{EXTENDED ABSTRACT}

When the growth processes of countries are examined, it is known that some countries perform much faster economic growth than others. In current growth theories, human capital and technology have become factors explaining growth and income differences Keynesian models give notice that growth can be achieved not only by increases in factors of production but also by reallocating existing resources from the inefficient non-export sector to the more productive export sector. According to this traditional view, an increase in export volume will have a positive effect on growth. The mentioned effect is experienced through foreign demand created by the increase in exports, resource allocation, economies of scale, technology diffusion, increasing total factor productivity, and contributing to free trade. One step further, it is argued that high-tech industries are the sectors that contribute the most to the international competitive performance of countries and that world trade in high-tech industries stimulates growth much more than in other manufacturing industries. Diversification of exports from primary goods to high value-added technology-intensive goods will allow more technological spillover to sectors than traditional product exports provide and will contribute to decimating the technology gap between countries.

This study aims to present new findings to the literature by analyzing the impact of high-tech(HT) exports on revenue using panel data methods in 49 countries and under both Cobb-Douglas and Translog production functions for the period 19882017. The common point of previous studies is that they explain these relations under the Cobb-Douglas (C-D) production function. No other study has been found in the literature investigating the HT-Income relationship in the Translog production function. In this aspect, the current analysis is a pioneer study. 
Regression coefficients were estimated by the Driscoll-Kraay method, which produces robust standard errors in cases where OLS assumptions cannot be met. Furthermore, the existence of cointegration between the series was investigated by the stationarity of the residuals. The stationarity of the regression residuals indicates that the estimated regression coefficients are not spurious and the obtained statistics can be interpreted with confidence. Since the series are cointegrated, regression analyzes can be interpreted in the long term.

According to the findings, the income elasticity of the physical capital contributing to the scale is 0.668 ; income elasticity of human capital was calculated as 0.584 and income elasticity of $\mathrm{HT}$ exports was calculated as 0.071. HT export-oriented technology-intensive policies will contribute positively to income.However, HT exports have been found to contribute to income per labor force, while human capital contributes to income per labor force along an increasing curve. The relationship between physical capital and income seems decidedly linear. When the substitution elasticities are examined, it is seen that the substitution relationship between physical and human capital is weak and there are complementary factors. Human capitalHT; physical capital-HT factors are factors that can be substituted for each other. These findings were tested for robustness with alternative regression methods in addition to the main models, and results compatible with the existing models were obtained.

The fact that human capital contributes to income along a curve that increases non-linearly emphasizes the importance of this factor for countries. This characteristic of human capital as the determinant of the condition of increased returns on the scale and the dominant factor determining income shows that the policies to increase high-tech exports recommended to countries to get out of the middle-income trap can actually be a supporting element that complements human capital. Therefore, policies that will basically increase the quantity and quality of education will both stimulate income growth and contribute to the reduction of social problems such as gender inequality. 
Accordingly, policies must be designed for the establishment of technologyintensive free zones, the provision of the logistics infrastructure of these zones, encouraging foreign investment and trade, increasing institutional quality, etc. 


\section{Giriş}

Ülkelerin büyüme serüvenleri incelendiğinde bazı ülkelerin diğerlerinden çok daha hızlı ekonomik büyüme performansı gösterdikleri bilinmektedir. Bu farklılıklar Solow (1957) ile birlikte teknoloji faktörüyle açıklanmaktadır. Ancak burada teknoloji, kamusal bir mal olarak her ülkenin küresel teknoloji havuzundan bedelsiz olarak yararlanacağı bir mühendislik faaliyeti olarak tanımlanmıştır. Sonraki ampirik çalışmalar Romer (1986), Lucas (1988), Mankiw, Romer ve Weil (1992) fiziksel ve beşeri sermaye birikimlerinin, bunların yanı sıra Ar-Ge yatırımlarının teknolojik gelişmelere yol açtığını (Coe ve Helpman, 1995; Aghion ve Howitt, 1998), teknolojinin kamusal bir mal olmadığını varsaymaktadır. Böylelikle beşeri sermaye ve teknoloji, büyüme farklılıklarını açıklayan faktörler haline gelmiştir.

Diğer yandan Keynesyen ihracata dayalı büyüme modellerinde, Feder (1983) ile birlikte ihracat ve ihracat dışı sektörler arasındaki verimlilik farklılıkları analitik bir çerçevede açıklanmaktadır. Ekonominin ihracat ve ihracat dışı sektörlerinde marjinal faktör verimliliklerinin eşit olmadığı marjinal faktör verimliliklerinin ihracatta belirgin şekilde yüksek olduğu ve verimlilik farkının ihracatın yarattığı sektörler arası pozitif dışsallıklardan kaynaklandığı gösterilmiştir. Sonuç olarak büyümenin yalnızca üretim faktörlerindeki artışlarla değil, aynı zamanda mevcut kaynakların verimli olmayan ihracat dışı sektörden daha yüksek verimli ihracat sektörüne yeniden tahsis edilmesiyle elde edilebileceği sonucuna varılmıştır. Bu geleneksel görüşe göre, ihracat hacminin artması büyüme üzerinde olumlu bir etki yaratacaktır. Söz konusu etki, ihracat artışının yarattığı dış talep, kaynak tahsisi, ölçek ekonomileri, teknoloji yayılması, toplam faktör verimliliğini artırması ve serbest ticarete katkı vermesi aracılığıyla yaşanmaktadır.

Bunun bir adım ötesinde yüksek teknolojili endüstrilerin, ülkelerin uluslararası rekabet performansına en çok katkı veren sektörler olduğu, yüksek teknoloji sanayilerinde dünya ticaretinin, diğer imalat sanayilerinde olduğundan çok daha fazla büyümeyi uyardığı ileri sürülmektedir (Yoo, 2003; Cuaresma ve Wörz, 2005). İhracatın gelir ve büyümeyi desteklemesinde, hacmiyle birlikte kompozisyonunun da çok önemli olduğunu vurgulayan bu bakış açısı, ülkenin yerel teknoloji 
kapasitesinin göstergesi olarak yüksek teknoloji (HT) ihracatı artışlarının büyümeyi diğer sektörlerden daha çok artırması anlamına gelmektedir. Bununla birlikte ihracatın birincil mallardan yüksek katma değerli teknoloji yoğun mallara yönelik çeşitlendirilmesi, geleneksel ürün ihracatının sağladığından daha fazla sektöre teknolojik yayılma sağlayacak ve ülkeler arasındaki teknoloji açı̆̆ının azalmasına katkıda bulunacaktır (Herzer ve Nowak-Lehmann, 2006).

Bu görüşlerin ışığında mevcut literatürde birçok çalışma çıktı(gelir) ve/veya büyümenin açıklayıcı değişkeni olarak HT ihracatının ve çeşitli makro iktisadi değişkenlerin yer aldığı ampirik modellerle söz konusu hipotezleri test etmektedir. Yapılan çalışmaların ortak noktası Cobb-Douglas (C-D) üretim fonksiyonu altında söz konusu ilişkileri açıklamalarıdır. Mevcut çalışmada Yoo (2008) ve Falk (2009) çalışmaları izlenerek C-D üretim fonksiyonunda HT ihracatının gelire olan katkısı farklı bir ülke grubu ve dönem için araştırılmıştır. Bununla birlikte ikinci model olarak translog üretim fonksiyonu koşullarında HT ihracatının gelir üzerindeki etkisi ilk kez ele alınmaktadır.

\section{Yüksek Teknoloji İhracatında Mevcut Durum}

Bu kısımda ülkeler ve Türkiye özelinde yüksek teknoloji ihracatına dair mevcut veriler yorumlanacaktır. İlk olarak ülkelerin 2017 yılına ait gelir-yüksek teknoloji ihracatı dağılımı Şekil 1'de verilmektedir. 


\section{Şekil 1. Ülkelerin Gelir ve Teknoloji Eşleşmesi (2017)}

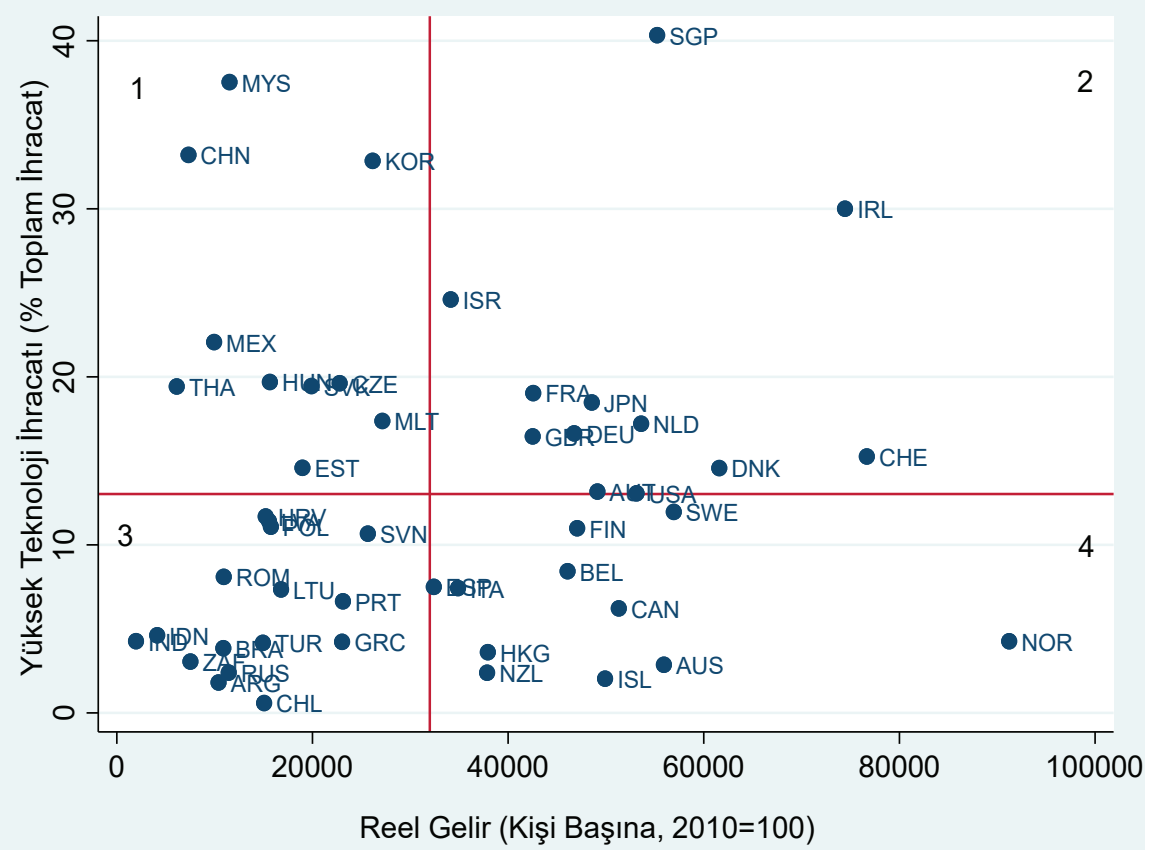

Şekil incelendiğinde, yüksek teknoloji ihracatı ve kişi başına düşen gelir düzeyi ülke ortalamalarını gösteren referans çizgileri dağılım alanını dört bölgeye ayırmaktadır. Örneklem ağırlıklı olarak OECD ülkelerinden oluştuğu için kişi başına gelir ortalaması 31.994 dolar olarak oldukça yüksek seviyede gerçekleşmiştir. Bu gelir seviyesine karşılık gelen ortalama yüksek teknoloji ihracatı ise \%13,02 düzeyindedir. 1 numaralı bölgedeki ülkelerde yüksek teknoloji ihracatı oldukça yüksek olmasına rağmen gelir düzeyi ortalamanın altında kalmaktadır. Singapur, Malezya, Çin ve Güney Kore yüksek teknoloji ürün ihracatında diğer ülkelerden oldukça ilerdedir. Bu ülkelerde yüksek teknoloji ihracatı \%30 düzeyinin üzerindedir. Ancak, bu bölgenin tipik özelliği yüksek teknoloji ürünlerin üreticisi olmaktan ziyade montajcısı durumunda olan uzak doğu ülkelerinin ve maliyet avantajına sahip olan Meksika, Macaristan ve Çek Cumhuriyeti gibi ekonomilerin yer almasıdır. 2 numaralı bölgede hem gelir düzeyi hem de yüksek teknoloji ihracatı bakımından lider ülkelerin olduğu görülmektedir. Bu bölgede Almanya, Japonya, Hollanda, Fransa, İsrail gibi gelişmiş ülkeler yer almaktadır. 3 numaralı bölgede ise hem gelir düzeyi 
hem de yüksek teknoloji ihracatında ortalama değerlerin altında kalan gelişmekte olan ülkeler ve OECD ekonomilerinin nispeten düşük gelirli örnekleri bulunmaktadır. Türkiye de bu grupta yer alan ülkeler arasındadır. Türkiye'de 2017 ylı için 14 bin dolar gelir seviyesine karşılık yaklaşık olarak \%4 yüksek teknoloji ihracat oranı eşlik etmektedir. Son bölge olan 4 numaralı alanda gelir düzeyi oldukça yüksek olmasına rağmen yüksek teknoloji ihracatında aynı performansı gösteremeyen ülkeler karşımıza çıkmaktadır. Bu bölgenin tipik özelliği Kanada hariç olmak üzere Norveç, İsviçre ve İzlanda gibi kişi başına düşen gelir düzeyiyle diğer gelişmiş ülkelerden pozitif ayrışan küçük refah devletlerinden oluşmasıdır.

Yüksek teknoloji ürün ihracatının ülkeler arası karşılaştırmalarda değişkenin oran veya yüzde (\%) şeklinde kullanılması ülkelerin dışa açıklık düzeyini ve ölçeğini göz ardı ettiği için sağlıklı bir karşılaştırma yapmaya elverişli bir değişken olmamakla birlikte benzer ülkeler için kullanılabilir. Bu nedenle ülkelerin karşılaştırması daha sağlıklı bilgiler elde edebilmek için işgücü başına düşen teknoloji ihracatıyla da yapılmıştır. Ülkelerin 2017 yılına ait gelir-kişi başına yüksek teknoloji ihracatı dağııımı Şekil 2'de verilmektedir.

Şekil 2. Ülkelerin Kişi Başına Gelir ve Teknoloji Eşleşmesi (2017)

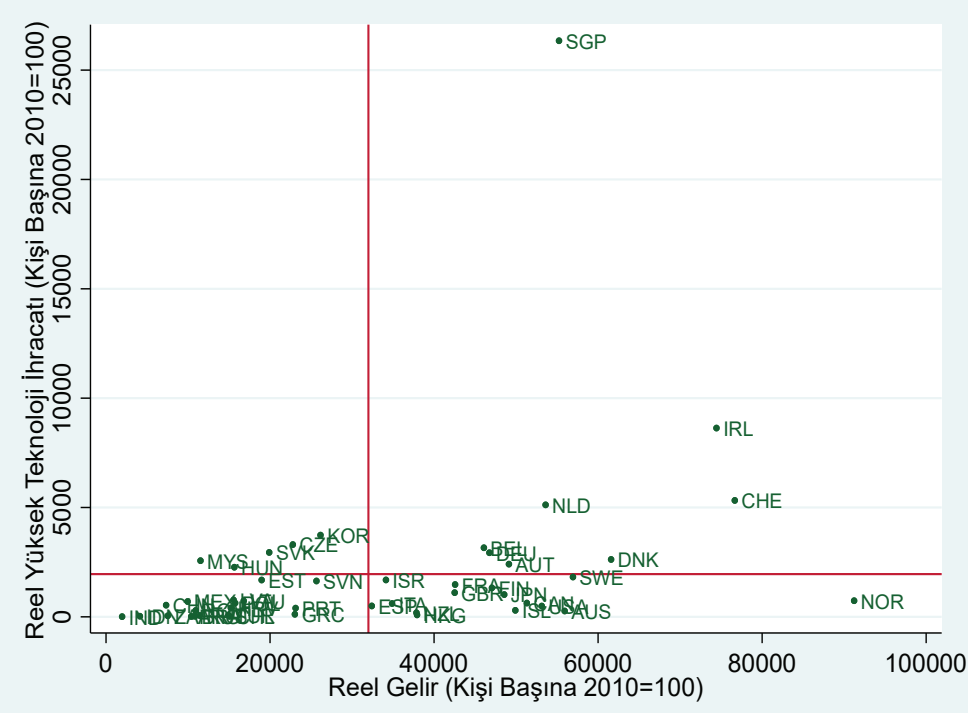


Şekil 1 ve 2 birlikte incelendiğinde HT ihracatı, \% olarak ölçülmesine kıyasla kişi başına düşen verilerle ölçüldüğünde daha kümelenmiş ve daha az aykırı değere (outlier) sahiptir. Şekil 2'de ortalama değerlere yakınsayan çok sayıda ülke olduğu görülmektedir. Özellikle gelişmekte olan Asya ülkelerinde bu sapma çok daha belirgindir. Singapur her iki dağılımda da aykırı gözlem (outlier) olma durumundadır. İrlanda, Hollanda ve İsviçre kişi başına düşen reel yüksek teknoloji ihracatında 5 bin dolar seviyesini aşan lider ülkeler olarak dağılımdan pozitif ayrılırken Norveç 90 bin dolar reel gelir düzeyini aşan örneklemdeki tek ülkedir. Tablo 1'de gelir ve yüksek teknoloji ihracatına dair özet veriler sunulmuştur.

Tablo 1: Yüksek Teknoloji İhracatı ve Refah Düzeyi

\begin{tabular}{|c|c|c|c|c|c|c|c|}
\hline \multicolumn{8}{|c|}{ Panel A: 2017 Yılına Ait Veriler } \\
\hline Ülke & YIl & Sira & $\begin{array}{c}\text { Reel Gelir } \\
\text { (Kişi Başına \$) }\end{array}$ & $\begin{array}{c}\text { Reel HT } \\
\text { (Kişi Başına \$) }\end{array}$ & $\Delta$ Sıra & $\begin{array}{l}\text { Ortalama HT } \\
\text { Büyümesi }\end{array}$ & $\begin{array}{l}\text { Ort. Gelir } \\
\text { Büyümesi }\end{array}$ \\
\hline Singapur & 2017 & 1 & $55.235,5$ & $26.342,8$ & 0 & 0,05 & 0,03 \\
\hline İrlanda & 2017 & 2 & $74.433,5$ & $8.632,7$ & 0 & 0,05 & 0,04 \\
\hline İsviçre & 2017 & 3 & $76.667,4$ & $5.322,8$ & 1 & 0,05 & 0,01 \\
\hline Hollanda & 2017 & 4 & $53.597,8$ & $5.120,0$ & 1 & 0,05 & 0,02 \\
\hline G. Kore & 2017 & 5 & $26.152,0$ & $3.736,4$ & 17 & 0,08 & 0,04 \\
\hline Türkiye & 2017 & 42 & $14.933,3$ & 76,9 & 5 & 0,10 & 0,03 \\
\hline Brezilya & 2017 & 45 & $10.889,0$ & 37,9 & -5 & 0,03 & 0,01 \\
\hline Endonezya & 2017 & 46 & $4.130,7$ & 29,6 & 2 & 0,11 & 0,03 \\
\hline Arjantin & 2017 & 47 & $10.398,1$ & 22,7 & -5 & 0,04 & 0,01 \\
\hline Şili & 2017 & 48 & $15.059,5$ & 22,6 & -2 & 0,05 & 0,03 \\
\hline Hindistan & 2017 & 49 & $1.963,6$ & 8,9 & 0 & 0,09 & 0,05 \\
\hline Ortalama & & & $31.994,3$ & $1.923,0$ & & & \\
\hline \multicolumn{8}{|c|}{ Panel B: 1988 Yılına Ait Veriler } \\
\hline Singapur & 1988 & 1 & $19.583,5$ & $5.134,6$ & & & \\
\hline İrlanda & 1988 & 2 & $20.598,0$ & $1.678,7$ & & & \\
\hline Hong Kong & 1988 & 3 & $17.421,1$ & $1.494,5$ & & & \\
\hline İsviçre & 1988 & 4 & $60.588,6$ & $1.357,3$ & & & \\
\hline Hollanda & 1988 & 5 & $33.039,8$ & $1.081,4$ & & & \\
\hline Çin & 1988 & 45 & 695,6 & 4,7 & & & \\
\hline Şili & 1988 & 46 & $5.413,3$ & 4,4 & & & \\
\hline Türkiye & 1988 & 47 & $6.404,0$ & 4,1 & & & \\
\hline Endonezya & 1988 & 48 & $1.536,3$ & 1,1 & & & \\
\hline Hindistan & 1988 & 49 & 500,0 & 0,5 & & & \\
\hline \multicolumn{3}{|l|}{ Ortalama } & $18.859,1$ & 439,4 & & & \\
\hline
\end{tabular}

Not. Sıralama kişi başına düşen reel yüksek teknoloji ihracatı verilerine; değişim dönem başına (1988) göre hesaplanmıştır. 
1988 yılı hesaplanan verilere göre oluşturulan sıralamada Singapur ilk sırada yer almaktadır. İncelenen dönemin son yılı olan 2017 yılı itibariyle de Singapur kişi başına düşen reel yüksek teknoloji ihracatında lider olma konumunu sürdürmüştür. Ancak burada dikkat edilmesi gereken nokta uzak doğu ekonomileri için değinilen montajlanmış yüksek teknolojinin varlığıdır. Sıralamada en başarılı performansı gösteren ülkeler Slovakya (23 sıra), Çek Cumhuriyeti (22) ve Güney Kore (17) olarak hesaplanmıştır. Hindistan periyot boyunca en düşük kişi başına reel HT ihracatı değerine sahip ülke olma durumundadır. Ülke ortalamaları ise 439 dolar seviyesinden 1923 dolar düzeyine çıkmıştır.

Türkiye sıralamada 5 basamak yükselerek 47. Sıradan 42. Sıraya ilerlemiştir. Uzun dönem ortalama gelir büyümesi \%2,82; ortalama yüksek teknoloji büyümesi ise \%9,77 olmuştur. Türkiye'de yıllara göre kişi başına düşen reel yüksek teknoloji ihracatının seyri ise Şekil 3'te verilmektedir.

Şekil 3. Türkiye'de Yıllara Göre Yüksek Teknoloji İhracatı

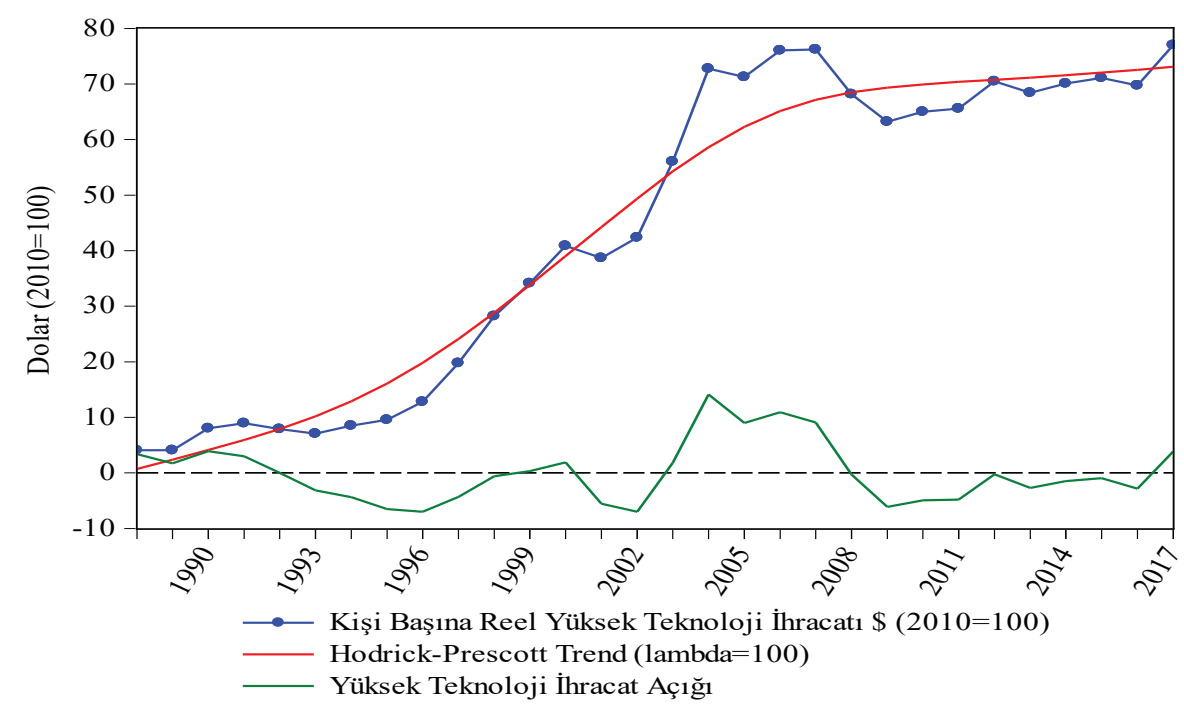

İncelenen otuz yıllık dönemde kişi başına düşen reel yüksek teknoloji ihracatı 4 dolardan 76 dolar düzeyine çıkmışırı. Örneklem ortalamasının 2017 yılı için 1.923 dolar olduğu göz önüne alındığında Türkiye, ortalamanın oldukça uzağındadır. 
Dağılımın seyri incelendiğinde kişi başına reel yüksek teknoloji ihracatı konjonktür dalgalarına benzer bir yapıdadır. Yüksek teknoloji ihracatı trendin etrafında dönmekte ve bu periyot yaklaşık olarak 7-8 yıl sürmektedir. Dip ve tepe noktaları arasındaki farkın giderek kapanması gözlemlenen diğer bir bulgudur. Bu durum Türkiye'de yüksek teknoloji ihracatının dışsal şoklara giderek direnç kazanması anlamına gelir.

Şekil 4'te ülkelerin 1988 ve 2017 yıllarına ait reel kişi başına yüksek teknoloji eşleşmesi verilmiştir. Grafik özet olarak, analiz edilen periyodun tamamında ülkelerin gösterdiği performansı sunmaktadır.

Şekil 4. Kişi başına reel yüksek teknoloji ihracatı 1988-2017 (Dolar, 2010=100)

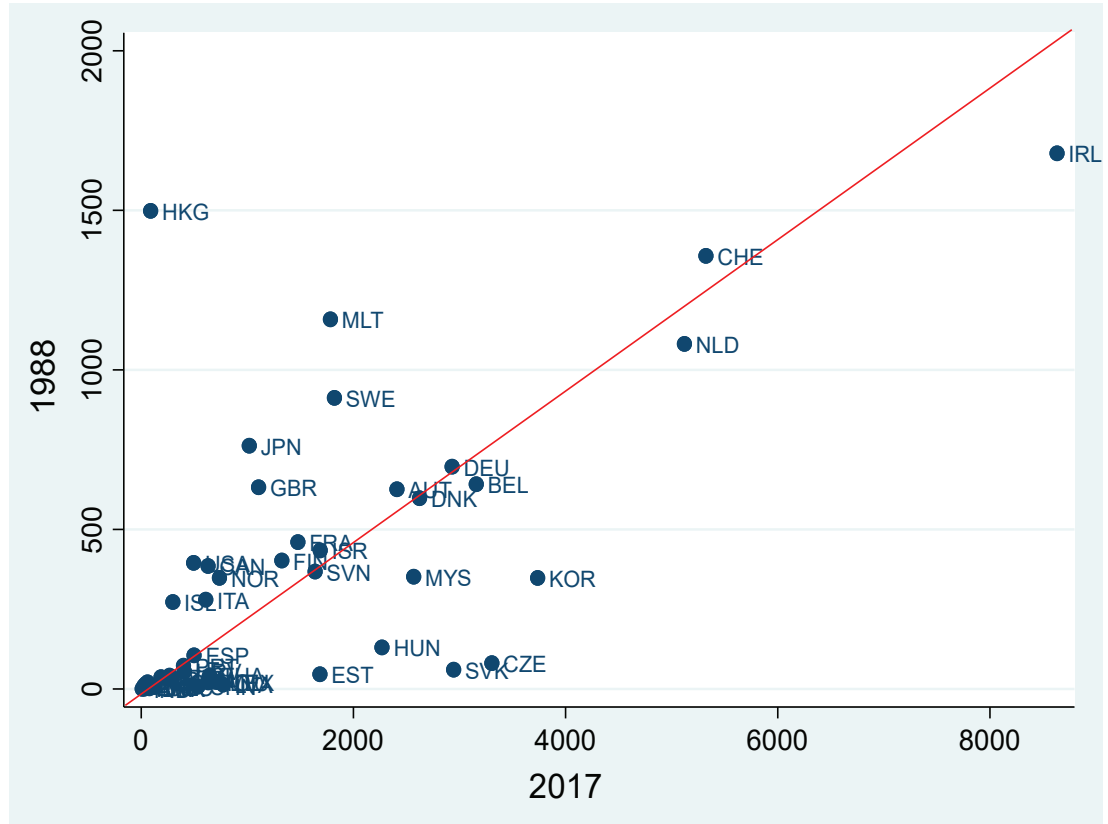

Singapur ölçek dışı performans göstermesi nedeniyle grafikten çıkarılmıştır. Kırmızı ile gösterilen $45^{\circ}$ referans çizgisinin üzerinde kalan ülkeler altında kalan ülkelere göre kişi başına yüksek teknoloji artışında daha düşük bir performans göstermiştir. Çok sayıda ülke $1988=250$ \$ ve $2017=1.000$ \$ aralığında kümelenmiş durumdadır. 


\section{Translog Üretim Fonksiyonu}

Üretim fonksiyonu, en yalın haliyle üretim girdileri ve toplam çıktı arasındaki matematiksel ve fonksiyonel ilişkiyi vermektedir. Üretim fonksiyonu firma/sektör gibi birimlerde mikro düzeyde ele alınabildiği gibi ülke ölçeğinde makro düzeyde analize de olanak tanır. İster mikro düzeyde isterse makro düzeyde olsun üretim fonksiyonu; üretim tekniği, ikame esneklikleri, girdilerin marjinal verimlilikleri, ölçek esnekliği gibi önemli iktisadi bilgileri içerir. Bununla birlikte, veri teknoloji varsayımı altında girdilerin ne derecede etkin kullanıldığı ve faktör fiyatlarından hareketle optimum kaynak kullanımı bileşimi üretim fonksiyonundan elde edilir.

Matematiksel formuna bağlı olarak lineer, kuadratik, kübik formlarda birçok üretim fonksiyonu tanımlanabileceği gibi iktisat disiplininde bilinen formlar CobbDouglas (Cobb ve Douglas, 1928), Translog (Christensen, Jorgenson \& Lau, 1973; Berndt ve Christensen, 1973), CES (Arrow, Chenery, Minhas \& Solow, 1961; Paroush, 1966; Kmenta, 1967), VES (Revankar, 1971), Stone-Geary (Geary, 1950; Stone, 1954) ve Leontief (Leontief, 1941; Walras, 1954; Morishima, 1963) üretim fonksiyonlarıdır.

Translog üretim fonksiyonu (Transcendental Logarithmic Production Function), Christensen vd. (1973) çalışmasında iktisat literatürüne girerek firma, endüstri ve ülkenin üretim yapısını analiz etmek için önemli bir araç haline gelmiştir. Translog üretim foksiyonu, ikame esneklikleri ve ölçeğe göre getiriler üzerinde varsayımsal olarak hiçbir apiori sınırlamada bulunmaz. Bu nedenle fonksiyonda her üretim düzeyi için farklı bir ikame esnekliği söz konusu olmaktadır (Berndt ve Christensen, 1973). Dolayısıyla ampirik analizlerde faktör ikame katsayılarını incelemek için geniş bir kullanım alanına sahiptir. Ayrıca, yaygın olarak kullanılan ve ikame esnekliği 1'e eşit olan Cobb-Douglas formu, translog üretim fonksiyonunun özel bir durumudur (Kim, 1992). İki üretim girdisinin kullanıldığı translog üretim fonksiyonun genel formu Eşitlik 1'de verilmektedir. Girdi sayısı arttıkça girdilerin birbiriyle etkileşimi ve kuadratik terimlerinin modele eklenmesi gerekir.

$$
\ln Q=\alpha_{0}+\alpha_{K} \ln K_{t}+\alpha_{L} \ln L_{t}+\alpha_{K L} \ln K_{t} \ln L_{t}+\left(\frac{1}{2}\right) \alpha_{K K}\left(\ln K_{t}\right)^{2}+\left(\frac{1}{2}\right) \alpha_{L L}\left(\ln L_{t}\right)^{2}
$$


Fonksiyonda, $\mathrm{Q}$ toplam çıktı veya üretim düzeyini, $\mathrm{K}$ sermaye stokunu, $\mathrm{L}$ işgücünü; $\alpha_{0}$ sabit terimi; $\alpha_{i}$ faktör katsayılarını temsil etmektedir. Translog üretim fonksiyonunda, tahmin edilen regresyon katsayıları C-D üretim fonksiyonunda olduğu gibi esneklikleri vermemektedir. Girdilerin esneklikleri, üretim fonksiyonunda her bir girdiye göre kısmi türev alınarak hesaplanmaktadır. İki faktörlü bir modelde, sermayenin ve emeğin çıktı esnekliği 2 ve 3 numaralı eşitliklerde verilmektedir. Sermayenin esnekliği;

$$
\varepsilon_{K}=\frac{d Q / Q}{d K / K}=\frac{d \ln Q_{t}}{d \ln K_{t}}=\alpha_{K}+\alpha_{K L} \ln L_{t}+\alpha_{K K} \ln K_{t}
$$

Emeğin esnekliği;

$$
\varepsilon_{L}=\frac{d Q / Q}{d L / L}=\frac{d \ln Q_{t}}{d \ln L_{t}}=\alpha_{L}+\alpha_{K L} \ln K_{t}+\alpha_{L L} \ln L_{t}
$$

Faktör esnekliklerinden hareketle ölçek esnekliğinin hesaplanması ise aşağıdaki gibidir (Lin ve Xie, 2014).

$$
\begin{aligned}
& \varepsilon=\varepsilon_{K}+\varepsilon_{L} \\
& \varepsilon=\left(\alpha_{K}+\alpha_{K L} \ln L_{t}+\alpha_{K K} \ln K_{t}\right)+\left(\alpha_{L}+\alpha_{K L} \ln K_{t}+\alpha_{L L} \ln L_{t}\right) \\
& \varepsilon=\alpha_{K}+\alpha_{L}+\alpha_{K L} \ln K_{t}+\alpha_{K L} \ln L_{t}+\alpha_{K K} \ln K_{t}+\alpha_{L L} \ln L_{t}
\end{aligned}
$$

Çıktı esnekliği, ceteris paribus, üretim faktöründe meydana gelen yüzdesel değişimin çıktı miktarında yol açacağı yüzdesel değişim oranı olarak ifade edilmektedir.

Üretim fonksiyonunda da faktörler arasındaki ikame edilebilirlik derecesi, ikame esnekliği ile ölçülmektedir. İkame esnekliği, veri teknoloji varsayımında, marjinal teknik ikame oranındaki yüzde değişimin girdi oranındaki yüzde değişime oranı olarak hesaplanır. Sermaye ve emek arasındaki ikame esnekliği izleyen eşitliklerde verilmektedir.

$$
\sigma_{K L}=\frac{\frac{d(K / L)}{K / L}}{\frac{d\left(M P_{L} / M P_{K}\right)}{M P_{L} / M P_{K}}}
$$


Marjinal fiziksel ürünler ikame esnekliğinden hareketle aşağıdaki gibi yeniden yazıldığında;

$$
\frac{M P_{L}}{M P_{K}}=\frac{\frac{\partial Q}{\partial L}}{\frac{\partial Q}{\partial K}}=\frac{\varepsilon_{L}}{\varepsilon_{K}} \frac{K}{L}
$$

5 ve 6 numaralı denklem bir araya getirilip yeniden düzenlendiğinde;

$$
\sigma_{K L}=|1+|-\alpha_{K L}+\left(\frac{\varepsilon_{K}}{\varepsilon_{L}}\right) \alpha_{L L}\left|\left(-\varepsilon_{K}+\varepsilon_{L}\right)^{-1}\right|^{-1}
$$

ifadesi elde edilmektedir. Translog üretim fonksiyonunda $0 \leq \sigma \leq \infty$ arasında değişen değerler alabilir. Sıfır ikame esnekliği söz konusu olduğunda Leontief tipi üretim fonksiyonu geçerlidir ve faktörler birbiri yerine ikame edilemez. Sonsuz ikame esnekliğinin olduğu durumda ise üretim fonksiyonu, faktörlerin birbiriyle tamamen ikame edilebileceğini gösteren doğrusal üretim fonksiyonu halini alır ${ }^{1}$ (Lin ve Xie, 2014).

Ostbye'ye (2010) göre üçüncü dereceden terimler ekleyerek translog işlevini daha esnek hale getirmek mümkündür. İki faktörlü translog üretim fonkiyonunda, ikame esnekliği her zaman sıfırdan büyük olacaktır. Bununla birlikte, ikiden çok faktörlü fonksiyonda, bazı faktör çiftlerinin ikame ve diğerlerinin tamamlayıcı olması mümkündür. Bu durumda tamamlayıcı çiftler için ikame esnekliği negatif olması muhtemeldir (Debertin, 2012). Ancak böyle bir durum iktisadi olarak anlamsız olmakla birlikte teorik olarak mümkündür. Negatif ikame esnekliği üretimde bir girdinin kullanımının azaltılmasının, diğer faktörün üretimden çekilmesiyle aynı üretim düzeyinde kalınabileceği anlamına gelir. İki girdi arasındaki çapraz fiyat esnekliğinin negatif (tamamlayıcı olduklarını gösterir) ve mutlak değer olarak kendi fiyat esnekliğinden daha büyük olmasını gerektirecektir (Markandya ve Pedroso-Galinato, 2007).

\footnotetext{
${ }^{1}$ Cobb-Douglas üretim fonksiyonunda ise kuadratik ve etkileşim katsayıları olmadığı için $\alpha_{K K}=\alpha_{L L}=\alpha_{K L}=0$ 'dır. Buna bağlı olarak da $\varepsilon=\alpha_{K}+\alpha_{L}$ sabittir ve birim ikame esnekliği $\sigma=1$ söz konusudur (Miller, 2008).
} 


\section{Yüksek Teknoloji İhracatı ve Gelir Illişkisini İnceleyen Literatür}

İhracata dayalı büyüme (Export Led-Growth) hipotezini teorik temelde ortaya koyan çalışmalar sonrasında hipotezin test edilmesine yönelik birçok karşılaştırmalı ampirik çalışma yapılmış ve yapılmaya devam etmektedir. Ancak yüksek teknoloji ürün ihracatının gelir ve büyüme üzerindeki etkilerini inceleyen çalışmalar kısıtlı sayıdadır. Mevcut çalışmanın yöntemiyle uyumlu olarak literatür kısmında panel veri çalışmaları ele alınmış ve Tablo 2'de verilmiştir.

Tablo 2: HT İhracatının Gelir Düzeyi ve Büyüme Üzerine Etkisini Araştıran Literatür

\begin{tabular}{|c|c|c|c|c|c|}
\hline Yazarlar & $\begin{array}{c}\text { Ülke/Ülke } \\
\text { Grubu }\end{array}$ & Period & Açıklayıcı Değişkenler & Yöntem (Panel) & $\begin{array}{l}\text { Bağımlı } \\
\text { Değişken }\end{array}$ \\
\hline $\begin{array}{l}\text { Amable } \\
(2000)\end{array}$ & 39 & $\begin{array}{c}1965- \\
1990\end{array}$ & $\begin{array}{l}\text { HT İhracatında Mukayeseli } \\
\text { Üstünlük, Sektörler Arası } \\
\text { Uzmanlaşma, Ticaret } \\
\text { Farklılığı Endeksi, SCH, INV }\end{array}$ & GMM & $\Delta \mathrm{GSYH}$ \\
\hline $\begin{array}{l}\text { Plümper \& } \\
\text { Graff (2001) }\end{array}$ & 90 & $\begin{array}{c}1980- \\
1990\end{array}$ & HT, K, L, SCH, T, OPN & LSDV & $\Delta G S Y H$ \\
\hline $\begin{array}{l}\text { Peneder } \\
(2003)\end{array}$ & 28-OECD & $\begin{array}{c}1990- \\
1998\end{array}$ & $\begin{array}{l}\text { HT İhracatı, HT İthalatı, } \\
\text { SCH, INV, POP, EMP }\end{array}$ & FE & $\begin{array}{l}\text { GSYH, } \\
\triangle G S Y H\end{array}$ \\
\hline Yoo (2003) & 56 & $\begin{array}{c}1970- \\
1998\end{array}$ & $\begin{array}{l}\text { IT (Bilgi Teknolojileri } \\
\text { Yatırımları), K, SCH }\end{array}$ & $\begin{array}{l}\text { Havuzlanmış } \\
\text { SEK- } \\
\text { White Standart } \\
\text { hatalar } \\
\end{array}$ & GSYH \\
\hline $\begin{array}{l}\text { Cuaresma \& } \\
\text { Wörz (2005) }\end{array}$ & 45 & $\begin{array}{c}1981- \\
1997\end{array}$ & $\mathrm{HT}, \mathrm{K}, \mathrm{L}, \mathrm{LT}, \mathrm{NT}$ & GLS, EC2SLS & $\Delta G S Y H$ \\
\hline $\begin{array}{l}\text { Aiginger } \& \\
\text { Falk (2005) }\end{array}$ & 21-OECD & $\begin{array}{l}1970- \\
1999\end{array}$ & $\begin{array}{c}\text { HT, SCH, RD, OPN, TAX, } \\
\text { INV, PR, TT, LMR, GS, } \\
\text { GBD, vd. }\end{array}$ & GMM & $\Delta G S Y H$ \\
\hline Falk (2007) & 19-OECD & $\begin{array}{l}1970- \\
2004\end{array}$ & HT, HT-RD, SCH, INV, RD & GMM & GSYH \\
\hline $\begin{array}{l}\text { Madsen } \\
(2007)\end{array}$ & 16-OECD & $\begin{array}{l}1870- \\
2004 \\
\end{array}$ & HT İthalatı, PR(Patent) & Havuzlanmış SEK & TFP \\
\hline $\begin{array}{l}\text { Fagerberg } \\
\text { vd. (2007) }\end{array}$ & 90 & $\begin{array}{l}1980- \\
2002\end{array}$ & $\begin{array}{c}\text { Teknoloji Endeksi, } \\
\text { Teknolojik Kapasite } \\
\text { Endeksi, RP (Göreli Fiyat), } \\
\text { D (Talep) }\end{array}$ & Havuzlanmış SEK & $\triangle G S Y H$ \\
\hline Yoo (2008) & 91 & $\begin{array}{l}1988- \\
2000\end{array}$ & $\mathrm{HT}, \mathrm{K}, \mathrm{SCH}$ & $\begin{array}{l}\text { Havuzlanmış } \\
\text { SEK- } \\
\text { White Standart } \\
\text { hatalar }\end{array}$ & GSYH \\
\hline Gani (2009) & 45 & $\begin{array}{l}1996- \\
2004\end{array}$ & $\begin{array}{l}\text { HT, SCH, INV, INF, POP, } \\
\text { INGDP }\end{array}$ & GLS, FE & $\Delta \mathrm{GSYH}$ \\
\hline
\end{tabular}


Tablo 2: HT İhracatının Gelir Düzeyi ve Büyüme Üzerine Etkisini Araştıran Literatür

\begin{tabular}{|c|c|c|c|c|c|}
\hline Yazarlar & $\begin{array}{l}\text { Ülke/Ülke } \\
\text { Grubu }\end{array}$ & Period & Açıklayıcı Değişkenler & Yöntem (Panel) & $\begin{array}{l}\text { Bağımlı } \\
\text { Değişken }\end{array}$ \\
\hline Falk (2009) & 22-OECD & $\begin{array}{c}1980- \\
2004\end{array}$ & $\mathrm{HT}, \mathrm{SCH}, \mathrm{INV}, \mathrm{RD}$ & GMM & $\Delta G S Y H$ \\
\hline $\begin{array}{l}\text { Minondo } \\
(2010)\end{array}$ & $\begin{array}{l}\text { İspanya } \\
\text { Şehirleri }\end{array}$ & $\begin{array}{c}1995- \\
2004\end{array}$ & EXPY Endeksi, SCH, VA & $\begin{array}{l}\text { Havuzlanmış } \\
\text { SEK, FE }\end{array}$ & $\triangle \mathrm{GSYH}$ \\
\hline $\begin{array}{l}\text { Naude, } \\
\text { Bosker \& } \\
\text { Matthee } \\
(2010)\end{array}$ & $\begin{array}{l}354 \text { Afrika } \\
\text { Alt Bölgesi }\end{array}$ & $\begin{array}{c}1996- \\
2001\end{array}$ & $\begin{array}{c}\text { İhracat Uzmanlaşma } \\
\text { Endeksi, SCH, DIST, OPN, } \\
\text { POP }\end{array}$ & $\begin{array}{l}\text { Mekansal } \\
\text { Regresyon }\end{array}$ & $\triangle \mathrm{GSYH}$ \\
\hline Lee (2011) & 71 & $\begin{array}{l}1980- \\
2004\end{array}$ & $\begin{array}{l}\text { HT, MT, MLT, LT, Balassa } \\
\text { Index, OPN }\end{array}$ & $\begin{array}{c}\text { GMM, } \\
\text { Havuzlanmiş SEK }\end{array}$ & GSYH \\
\hline $\begin{array}{l}\text { Jarreau } \\
\text { \& Poncet } \\
(2012)\end{array}$ & $\begin{array}{l}30 \text { Çin } \\
\text { Eyaleti }\end{array}$ & $\begin{array}{c}1997- \\
2009\end{array}$ & $\begin{array}{l}\text { HT, EXPY Endeksi, SCH, } \\
\text { INV, FDI, OPN, ZONE }\end{array}$ & SEK, FE & $\Delta G S Y H$ \\
\hline $\begin{array}{l}\text { Kılavuz \& } \\
\text { Altay Topçu } \\
\text { (2012) }\end{array}$ & $\begin{array}{c}22 \\
\text { Gelişmekte }\end{array}$ & $\begin{array}{c}1998- \\
2006\end{array}$ & $\begin{array}{l}\mathrm{HT}, \mathrm{HT} \text { İthalatı, LT, LT } \\
\text { İthalatı, INV }\end{array}$ & $\begin{array}{c}\text { SEK, RE, FE ve } \\
\text { PCSE }\end{array}$ & GSYH \\
\hline $\begin{array}{l}\text { Santos vd. } \\
\text { (2013) }\end{array}$ & 23-EU & $\begin{array}{l}1995- \\
2010\end{array}$ & $\begin{array}{c}\text { HT, INF, INV, POP, PRT, } \\
\text { GPRT, HHI Endeksi, Tarım; } \\
\text { Sanayi; Ham madde } \\
\text { İhracatı }\end{array}$ & $\mathrm{FE}$ & $\Delta G S Y H$ \\
\hline $\begin{array}{l}\text { Topallı } \\
(2015) \\
\end{array}$ & 6 & $\begin{array}{c}1989- \\
2013 \\
\end{array}$ & HT, GSYH, FDI & $\begin{array}{c}\text { Nedensellik } \\
\text { Analizi }\end{array}$ & $\begin{array}{l}\mathrm{HT}, \mathrm{GSYH}, \\
\text { FDI }\end{array}$ \\
\hline $\begin{array}{l}\text { Bal, Çiftçi, } \\
\text { İşcan \& } \\
\text { Serin (2016) }\end{array}$ & 10-OECD & $\begin{array}{c}2003- \\
2015\end{array}$ & $\mathrm{HT}$ & GMM & GSYH \\
\hline $\begin{array}{l}\text { Işık \& Kılınç } \\
(2016)\end{array}$ & $\begin{array}{c}12 \\
\text { Gelişmiş- } \\
\text { Türkiye } \\
\end{array}$ & $\begin{array}{c}1990- \\
2011\end{array}$ & $\mathrm{HT}, \mathrm{RD}$ & $\begin{array}{l}\text { PMGE, MGE ve } \\
\text { Eşbütünleşme }\end{array}$ & GSYH \\
\hline $\begin{array}{l}\text { Ribeiro, } \\
\text { Carvalho } \\
\text { \& Santos } \\
(2016) \\
\end{array}$ & 26-EU & $\begin{array}{c}1995- \\
2014\end{array}$ & $\begin{array}{c}\text { HT, INF, INV, POP, PRT, } \\
\text { GPRT, HHI Endeksi, Tarım; } \\
\text { Sanayi; Ham madde } \\
\text { İhracatı }\end{array}$ & $\mathrm{FE}$ & $\Delta \mathrm{GSYH}$ \\
\hline $\begin{array}{l}\text { Ekananda \& } \\
\text { Parlinggoman } \\
(2017) \\
\end{array}$ & 50 & $\begin{array}{c}1992- \\
2014\end{array}$ & HT, LT, FDI, L, INV, INGDP & FGLS & $\Delta G S Y H$ \\
\hline $\begin{array}{l}\text { Satrovic } \\
(2018)\end{array}$ & 70 & $\begin{array}{c}1995- \\
2015\end{array}$ & HT, FDI, GSYH & $\begin{array}{l}\text { Nedensellik, } \\
\text { Eşbütünleşme, } \\
\text { PVAR }\end{array}$ & $\begin{array}{l}\text { HT, FDI, } \\
\text { GSYH }\end{array}$ \\
\hline Kim (2019) & 14 & $\begin{array}{c}1996- \\
2013 \\
\end{array}$ & $\begin{array}{l}\text { RD, (RD HHI), (RD HHI) } \\
\text { INF, UNEMP, INV, FDI, EXP }\end{array}$ & GMM & $\Delta \mathrm{GSYH}$ \\
\hline $\begin{array}{l}\text { Erkişi \& } \\
\text { Boğa (2019) }\end{array}$ & 15-EU & $\begin{array}{c}1998- \\
2017\end{array}$ & HT, L, INV & $\begin{array}{c}\text { VAR, } \\
\text { Eşbütünleşme, } \\
\text { Nedensellik, MGE }\end{array}$ & GSYH \\
\hline $\begin{array}{l}\text { Fang vd. } \\
(2019)\end{array}$ & 34-OECD & $\begin{array}{c}2000- \\
2014\end{array}$ & $\begin{array}{l}\text { Ar-Ge ve Dış Ticaret } \\
\text { Sektörü Değişkenleri }\end{array}$ & $\begin{array}{c}\text { Genel Denge } \\
\text { Modeli }\end{array}$ & $\Delta \mathrm{GSYH}$ \\
\hline
\end{tabular}


Tablo 2: HT İhracatının Gelir Düzeyi ve Büyüme Üzerine Etkisini Araştıran Literatür

\begin{tabular}{|c|c|c|c|c|c|}
\hline Yazarlar & $\begin{array}{l}\text { Ülke/Ülke } \\
\text { Grubu }\end{array}$ & Period & Açıklayıcı Değişkenler & Yöntem (Panel) & $\begin{array}{l}\text { Bağımlı } \\
\text { Değişken }\end{array}$ \\
\hline $\begin{array}{l}\text { Avila- } \\
\text { Lopez, Lyu } \\
\text { \& Lopez- } \\
\text { Leyva (2019) }\end{array}$ & $\begin{array}{l}12 \text { Latin } \\
\text { Amerika }\end{array}$ & $\begin{array}{c}1996- \\
2015\end{array}$ & HT, PR, RD, STJ & $\begin{array}{l}\text { Nedensellik, } \\
\text { Eşbütünleşme, } \\
\text { PVAR }\end{array}$ & $\triangle \mathrm{GSYH}$ \\
\hline $\begin{array}{l}\text { Orviská, } \\
\text { Huňady, } \\
\text { Pisár \& } \\
\text { Hudson } \\
\text { (2019) }\end{array}$ & 61 & $\begin{array}{r}1993- \\
2012\end{array}$ & HT, STJ, PR, GSYH & $\begin{array}{l}\text { Nedensellik, } \\
\text { Eşbütünleşme, } \\
\text { FMOLS, DOLS }\end{array}$ & $\begin{array}{l}\text { HT, STJ, } \\
\text { PR, GSYH }\end{array}$ \\
\hline $\begin{array}{l}\text { Shimbov, } \\
\text { Alguacil } \\
\text { \& Suárez } \\
\text { (2019) }\end{array}$ & 5 Balkan & $\begin{array}{c}1996- \\
2015\end{array}$ & $\begin{array}{c}\text { EXPY, SCH, INV, OPN, INS, } \\
\text { FDI, EBRD }\end{array}$ & $\mathrm{FE}, \mathrm{GMM}$ & $\triangle \mathrm{GSYH}$ \\
\hline $\begin{array}{l}\text { Nguyen } \\
\text { \& Pham } \\
(2020)\end{array}$ & 21 & $\begin{array}{c}2006- \\
2017\end{array}$ & $\begin{array}{c}\text { HT, HT ithalatı, INF, TAX, } \\
\text { CC, GE }\end{array}$ & $\begin{array}{c}\text { PCSE (P. } \\
\text { Düzeltilmiş Std. } \\
\text { Hatalar) }\end{array}$ & GSYH \\
\hline $\begin{array}{l}\text { Yaman \& } \\
\text { Sungur } \\
(2020)\end{array}$ & 36-OECD & $\begin{array}{c}1999- \\
2017\end{array}$ & HT, GSYH (Büyüme) & $\begin{array}{l}\text { Nedensellik, } \\
\text { Eşbütünleşme }\end{array}$ & $\begin{array}{c}\mathrm{HT}, \\
\Delta \mathrm{GSYH}\end{array}$ \\
\hline $\begin{array}{l}\text { Chrid, Saafi } \\
\text { \& Chakroun } \\
(2020)\end{array}$ & 51 & $\begin{array}{c}1984- \\
2015\end{array}$ & $\begin{array}{c}\text { HT (ECI Endeksi), SCH, } \\
\text { INV, OPN, FDI }\end{array}$ & $\begin{array}{l}\text { Nedensellik, } \\
\text { Eşbütünleşme, } \\
\text { CCEMG }\end{array}$ & GSYH \\
\hline $\begin{array}{l}\text { Carrasco } \\
\text { \& Tovar- } \\
\text { García, } \\
(2020)\end{array}$ & $\begin{array}{c}19 \\
\text { Gelişmekte }\end{array}$ & $\begin{array}{c}1990- \\
2016\end{array}$ & $\begin{array}{c}\text { HT, HT İthalatı, SCH, INV, } \\
\text { INS, LAW, Herfindahl- } \\
\text { Hirschman Endeksi, TRC, TI }\end{array}$ & GMM & GSYH \\
\hline
\end{tabular}

Kısaltmalar: AP: Tarımda Verimlilik, CC: Yolsuzluk-Yozlaşma, EBRD: İ̧̧/Ticaret Atmosferi (Business Environment), EMP: İstihdam, EXD: Dış Borçlar, EXP: Toplam İhracat, GBD: Bütçe Açığı, GE: Hükümet Etkinliği, GS: Hükümet Harcamaları, HT: Yüksek Teknoloji İhracatı, INF: Enflasyon, INGDP: Başlangıç Yılı Gelir, INS: Kurumsal Kalite, INV: Sabit Sermaye Yatııımları, K: Sermaye Stoku, L: İşgücü, LAW:Yasal Güvence/Hukukun Üstünlüğü, LMR: Işsücü Piyasası Katılığı, LT: DüşüK Teknoloji İhracatı, NT: İmalat Sanayi Dışı İhracat, POP: Nüfus, PR: Patent Sayısı, PRT: Ticaret Partneri Sayısı, GPRT: Ticaret Partnerleri $\triangle$ GSYH, PSI: Politik İstikrar Endeksi, SCH: Beşeri Sermaye, STJ: Bilim ve Teknik Alanında Yayımlanan Bilimsel Makale Sayısı, T: Teknolojik İlerleme, TI: Ulusal Teknoloji Altyapısı, TT: Ticaret Koşulları, TRC: Ticaret Maliyeti, UNEMP: İsssizlik, VA: Katma Değer, ZONE: Özel Ekonomik Bölgeler, Ileri Teknoloji Sanayi Bölgeleri ve İhracat-Işleme Bölgeleri.

\section{Veri Setinin Hazırlanması ve Ekonometrik Model}

Oluşturulan veri seti 49 ülke ve 1988-2017 yıllarını içermektedir. Veri kalitesini korumak amacıyla yeterli ve sağlıklı verilere sahip olmayan ülkeler analize dahil edilmemiştir. Veri setinde yer alan ülkeler ekler kısmında verilmektedir.

Illk modelde Mankiw ve ark. (1992) modelini HT ihracatıyla genişleten Yoo (2003; 2008), Falk (2009), Kalaitzi ve Chamberlain (2020) çalışmaları izlenerek 
C-D üretim fonksiyonunda bağımlı değişken olarak işgücü başına düşen reel gelir ve açıklayıcı değişkenler olarak işgücü başına sermaye stoku, beşeri sermaye ve yüksek teknoloji ürün ihracatı değişkenleri yer almaktadır. İkinci modelde ise translog üretim fonksiyonuna bağlı olarak değişkenlerin kendilerinin yanı sıra birbirleriyle olan etkileşimleri ve kuadratik terimleri yer almaktadır.

Translog modelde etkileşim terimlerinin yer alması olası çoklu doğrusal bağlantı problemini gündeme getirmektedir. Çoklu doğrusal bağlantı varlığında SEK(OLS) tahmincisi yansızdır ve aslında en iyi doğrusal sapmasız tahminci olma özelliğini sürdürür. $\mathrm{R}^{2}$ istatistiği çoklu doğrusal bağlantıdan etkilenmez. Çoklu bağlantının istenmeyen en önemli sonucu, yüksek düzeyde korele değişkenlerin SEK parametreleri varyanslarının oldukça büyük olmasıdır (Kennedy, 2008). Çoklu doğrusal bağlantı sorunu polinom tipi modellerde, normalizasyon ile değişken dönüşümü, örneklem sayısını genişletmek, ridge regresyon, temel bileşenler (PCA), küçültülmüş (shrunk) regresyon ve kısmi en küçük kareler (PLS) aracılığıyla elimine edilebilmektedir (Shacham ve Brauner, 1997; O'Brien, 2007). İktisat uygulamalarında Translog üretim fonksiyonu formunda katsayı tahminleri yaparken etkileşim terimleri ve 2 . dereceden terimlerin yaratacağı olası çoklu doğrusal bağlantı problemini azaltmak için değişkenler yeniden ölçeklendirilerek normalize edilmektedir. Bir diğer uygulama olarak ise translog formasyonunda çoklu doğrusal bağlantı probleminden kaçınmak için sıklıkla Ridge Regresyon yöntemine başvurulmaktadır (Lin ve Ahmad, 2016). Normalizasyon yoluyla ortalama merkezleme (mean centering) çoklu doğrusal bağlantıyı zayıflatmaktadır (Kim, 1999; Jaccard ve Turrisi, 2003). Normalizasyon aynı zamanda değişen varyans durumunun azaltılmasına da yardımcı olmaktadır (Pablo-Romero ve Gomez-Calero, 2013; Kumbhakar, Lien \& Hardaker (2014); Kumbhakar, Wang \& Horncastle (2015). Bununla birlikte tüm değişkenlerin ortak bir ölçekte normalizasyonu değişkenleri birimlerinden arındırdığı için parametre değerlerinin doğrudan karşılaştırılmasına izin verir (Wooldridge, 2003). Bahsedilen yararları göz önüne alınarak modellerde kullanılan değişkenler Pablo-Romero ve Sánchez-Braza (2017), Du (2017) ve Pablo-Romero, Sánchez-Braza \& Expósito (2019) çalışmaları izlenerek kendi ortalamalarıla normalize edilmiştir².

\footnotetext{
2 Bu dönüşüm sonrasında elde edilen esneklik katsayıları matematiksel olarak örneklemin orta noktasına göre
} 
8 ve 9 numaralı eşitlikte verilen kapalı formda denklemler değişkenler arasındaki fonksiyonel ilişkiyi göstermektedir.

Model 1: Cobb-Dougles

$$
y=f\{k, h, h t\}
$$

Model 2: Translog

$$
y=f\left\{k, h, h t,(k \cdot h),(k \cdot h t),(h \cdot h t),\left(k^{2}\right),\left(h^{2}\right),\left(h t^{2}\right)\right\}(9)
$$

Kapalı formun açı ifadesi olan ampirik modeller ise aşağıdaki gibi ifade edilmektedir. Model 2'de 1 numaralı eşitlikte gösterilen translog formülasyonu kullanılmıştır.

Model 1:

$$
\ln \left(y_{p c}\right)_{i t}=\beta_{i 0}+\beta_{i 1} \ln (k)+\beta_{i 2} \ln (h)_{i t}+\beta_{i 3} \ln (h t)_{i t}+\varepsilon_{i t}
$$

Model 2:

$$
\begin{aligned}
& \ln \left(y_{p c}\right)_{i t}=\beta_{i 0}+\beta_{i 1} \ln (k)+\beta_{i 2} \ln (h)_{i t}+\beta_{i 3} \ln (h t)_{i t} \\
& +\beta_{i 4} \ln (k) \ln (h)+\beta_{i 5} \ln (k) \ln (h t)+\beta_{i 6} \ln (h) \ln (h t)_{i t} \\
& +\beta_{i 7}\left(\frac{1}{2}\right)(\ln k)^{2}+\beta_{i 8}\left(\frac{1}{2}\right)(\ln h)^{2}+\beta_{i 9}\left(\frac{1}{2}\right)(\ln h t)^{2}+\varepsilon_{i t}
\end{aligned}
$$

Illk açıklayıcı değişken olan sermaye stoku (k), işgücü başına düşen reel düzeyin logaritması olarak ifade edilmiştir. Sermaye stokunun hesaplanmasında Harberger (1978) Daimî Envanter Yöntemi (PIM) kullanılmış ve yıpranma payının Bosworth ve Collins (2003) çalışması izlenerek 0,05 olduğu varsayılmıştır. Başlangıç yılı sermaye stoku düzeyi, $K_{0}=I_{0} /(\delta+g)$ olarak hesaplanmaktadır. $I_{0}$ başlangıç yılı reel yatırım düzeyini, " $g$ " durağan durumda yatırımların büyüme oranını, " $\delta$ " ise sermaye stokunun yıpranma oranını temsil etmektedir. Buradan hareketle sermaye stoku aşağıdaki gibi elde edilir.

$$
K_{t}=(1-\delta) K_{t-1}+I_{t-1}
$$

Sermaye stoku tahmin edilen katsayı işaretinin teorik olarak pozitif olması $\beta_{i 1}>0$ beklenmektedir.

Uluslararası karşılaştırma yapabilmek amacıyla, ülkelerden oluşan panel veri yatay kesit setlerinde beşeri sermayenin vekil değişkeni olarak ortalama eğitim yılı değişkeni en yaygın kullanılan araçtır. Bu amaçla kullanılan iki farklı veri seti

yorumlanır (Pablo-Romero ve Sánchez-Braza, 2017; Pablo-Romero vd., 2019). Ancak ampirik çalışmalarda normalizasyon işleminden sonra çoğunlukla yapıldığı üzere bu çalışmada da değişkenler arasındaki esneklikler bu durum göz ardı edilerek yorumlanmaktadır. 
bulunmaktadır. Bunlardan ilki ve en yaygın kullanılanı Barro-Lee (2013) tarafından hesaplanan ortalama eğitim yılı değişkenidir. Diğer veri seti ise Cohen, Leker \& Soto (2014) çalışmasıdır. Yazarlar bu çalışmada 1950 yılından başlayan verilerle ve 2020 yılına yapılmış bir projeksiyonla hesaplamışlardır. Groningen Üniversitesi tarafından hazırlanan Penn World Table (PWT) veri tabanındaki beşeri sermaye endeksi de bu yazarların verilerine dayanarak hazırlanmıştır.

Tablo 3: Ortalama Eğitim Yılına İlişkin Veri Setleri

\begin{tabular}{|l|c|c|c|c|}
\hline Veri Seti & Ortalama & Standart Sapma & Minimum & Maksimum \\
\hline Barro-Lee Ortalama Eğitim Yılı & 5,4 & 3,3 & 0,1 & 13,4 \\
\hline Cohen-Soto-Leker Ort. Eğitim Yılı & 5,6 & 3,5 & 0,1 & 13,4 \\
\hline
\end{tabular}

Kaynak: Human capital in PWT 9.0 https://www.rug.nl/ggdc/docs/human_capital_in_pwt_90.pdf

Çalışmada, beşeri sermayenin hesaplanmasında yaygın kullanımı ve daha düşük standart sapmaya sahip olması nedeniyle Barro-Lee (2013) veri seti tercih edilmiştir. Bununla birlikte beşeri sermaye değişkeninin hesaplanmasında Mincerian yaklaşım takip edilerek eğitimin getirisi 0,07 kabul edilmiştir. Bir sonraki adımda ise yıllık ortalama çalışma saati (avh) değişkeniyle etkileşimi elde edilerek nihai beşeri sermaye değişkeni oluşturulmuştur.

$$
\begin{aligned}
& H=e^{(s c h * 0,07) * L} \quad \text { olmak üzere; } \\
& h=\frac{H}{L}=e^{(s c h * 0,07)}
\end{aligned}
$$

Beşeri sermaye ortalama çalışma saatiyle (avh) düzeltildiğinde ise;

$$
h=e^{(s c h * 0,07)} * a v h
$$

Beşerî sermayenin gelire verdiği katkının MRW (1992) modeli gereği teorik olarak pozitif olması $\left(\beta_{i 2}>0\right)$ beklenmektedir.

Bir diğer bağımsız değişken olan HT ihracatı işgücü başına reel olarak ölçülmektedir. İlgili değişken WITS veri tabanından ISIC Rev.3 kodlamasında ürün grubu bazında elde edilmiştir. HT ihracatının gelire olan etkisinin pozitif olması $\left(\beta_{i 3}>0\right)$ beklenmektedir. 
Translog üretim fonksiyonunda kullanılan diğer değişkenler teorik olarak bu üç değişkenin birbirleriyle olan etkileşimleri ve kuadratik terimleridir. Veri setini oluşturulmasına temel teşkil eden değişkenler ve elde edildiği kaynaklar izleyen tabloda verilmektedir.

Tablo 4: Değişkenler ve Veri Seti Kaynakları

\begin{tabular}{|l|c|c|c|}
\hline Değişkenler & Kısaltma & Ölçü Birimi & Veri Kaynağı \\
\hline $\begin{array}{l}\text { GSYH } \\
(2011=100, \text { Dolar) }\end{array}$ & $\ln (\mathrm{y})$ & $\begin{array}{c}\text { İşgücü başına reel değerin } \\
\text { doğal logaritması }\end{array}$ & PWT 9.1 \\
\hline Sermaye Stoku & $\ln (\mathrm{k})$ & $\begin{array}{c}\text { İşücü başına reel değerin } \\
\text { doğal logaritması }\end{array}$ & $\begin{array}{c}\text { PWT 9.1 veri tabanı yatırım } \\
\text { serisi ve sermaye stoku serisi }\end{array}$ \\
\hline Beşeri Sermaye & $\ln (\mathrm{h})$ & $\begin{array}{c}25+\text { ortalama eğitim yılı, } \\
\text { çalışma saati ve eğitimin } \\
\text { getirisi değişkenlerinin üstel } \\
\text { fonksiyonu }\end{array}$ & Barro-Lee (2013) \\
\hline $\begin{array}{l}\text { Yüksek Teknoloji } \\
\text { Ürün İhracatı }\end{array}$ & $\ln (\mathrm{ht})$ & $\begin{array}{c}\text { İşgücü başına reel değerin } \\
\text { doğal logaritması }\end{array}$ & WITS ve yazarın hesaplaması \\
\hline $\begin{array}{l}\text { İşgücü } \\
\text { Ortalama Çalışma }\end{array}$ & $\mathrm{L}$ & $\begin{array}{c}\text { İstihdam edilen kişi sayısı } \\
\text { düzey değeri }\end{array}$ & PWT 9.1 \\
\hline Saati & $\delta$ & $\begin{array}{c}\text { Yıllık Ortalama Çalışılan Saat } \\
\text { Amoüzde (\%) }\end{array}$ & PWT 9.1 \\
\hline
\end{tabular}

Not: Değişkenler logaritmaları alınmadan önce ortalamalarına bölünerek normalize edilme yöntemi kullanılmıştır.

\section{Ampirik Bulgular ve Ekonometrik Tahmin Sonuçları}

Model belirleme testlerine geçmeden önce, değişkenler arasındaki ilişkilerin apriori olarak belirlenmesi faydalı olacaktır. Bu doğrultuda, değişkenlere ait özet veriler ve korelasyon matrisi izleyen tabloda verilmiştir.

Tablo 5: Tanımlayıcı (Betimsel) İstatistikler

\begin{tabular}{|l|c|c|c|c|}
\hline Değişkenler & Ortalama & Standart Sapma & Minimum & Maksimum \\
\hline $\ln (\mathrm{y})$ & $-0,1496$ & 0,6146 & $-2,7047$ & 1,0666 \\
\hline $\ln (\mathrm{k})$ & $-0,1832$ & 0,6968 & $-3,2849$ & 0,7896 \\
\hline $\ln (\mathrm{h})$ & $-0,0125$ & 0,1597 & $-0,4913$ & 0,3477 \\
\hline $\ln (\mathrm{ht})$ & $-1,3011$ & 1,9076 & $-7,8224$ & 3,2680 \\
\hline $\ln (\mathrm{k}) \ln (\mathrm{h})$ & 0,022 & 0,162 & $-0,394$ & 1,154 \\
\hline $\ln (\mathrm{k}) \ln (\mathrm{ht})$ & 1,096 & 2,846 & $-1,891$ & 22,170 \\
\hline $\ln (\mathrm{h}) \ln (\mathrm{ht})$ & 0,115 & 0,487 & $-0,926$ & 3,348 \\
\hline
\end{tabular}




\begin{tabular}{|l|l|l|l|l|}
\hline$(\text { Ink })^{2}$ & 0,2594 & 0,6145 & 0,0000 & 5,3954 \\
\hline$(\text { Inh })^{2}$ & 0,0128 & 0,0170 & 0,0000 & 0,1207 \\
\hline$(\text { Inht })^{2}$ & 2,6647 & 4,3586 & 0,0000 & 30,5953 \\
\hline
\end{tabular}

Veriler incelendiğinde beşeri sermaye değişkeni ve onun sermaye stoku ile etkileşimi, varyansı dolayısıyla standart sapması en düşük değişkenler olduğu görülmektedir. Bunun yanı sıra HT ihracatı, minimum ve maksimum değer aralığı en geniş olan değişkendir. Bu durum ülkeler arasında ve/veya zaman aralığında bir teknolojik fark (gap) olduğunun göstergesidir. Değişkenler arasındaki korelasyonu gösteren Tablo 6 ise aşağıda verilmektedir.

Tablo 6: Korelasyon Matrisi

\begin{tabular}{|c|c|c|c|c|c|c|c|c|c|c|}
\hline & $\ln (y)$ & $\ln (k)$ & $\ln (h)$ & $\ln (h t)$ & $\begin{array}{l}\ln (k) \\
\ln (h)\end{array}$ & $\begin{array}{l}\ln (k) \\
\ln (h t)\end{array}$ & $\begin{array}{l}\ln (h) \\
\ln (h t)\end{array}$ & $(\text { Ink })^{2}$ & $(\operatorname{lnh})^{2}$ & $(\operatorname{lnht})^{2}$ \\
\hline $\ln (y)$ & 1,000 & & & & & & & & & \\
\hline $\ln (k)$ & 0,914 & 1,000 & & & & & & & & \\
\hline $\ln (h)$ & 0,233 & 0,156 & 1,000 & & & & & & & \\
\hline $\ln (\mathrm{ht})$ & 0,680 & 0,692 & 0,334 & 1,000 & & & & & & \\
\hline $\ln (k) \ln (h)$ & $-0,582$ & $-0,543$ & $-0,391$ & $-0,472$ & 1,000 & & & & & \\
\hline $\begin{array}{l}\ln (k) \\
\ln (h t) \\
\end{array}$ & $-0,759$ & $-0,799$ & $-0,332$ & $-0,646$ & 0,804 & 1,000 & & & & \\
\hline $\begin{array}{l}\ln (h) \\
\ln (h t)\end{array}$ & $-0,476$ & $-0,436$ & $-0,632$ & $-0,384$ & 0,830 & 0,662 & 1,000 & & & \\
\hline$(\operatorname{lnk})^{2}$ & $-0,734$ & $-0,760$ & $-0,303$ & $-0,505$ & 0,765 & 0,916 & 0,576 & 1,000 & & \\
\hline$(\operatorname{lnh})^{2}$ & $-0,249$ & $-0,256$ & $-0,324$ & $-0,266$ & 0,471 & 0,378 & 0,645 & 0,303 & 1,000 & \\
\hline$(\operatorname{lnht})^{2}$ & $-0,678$ & $-0,695$ & $-0,325$ & $-0,833$ & 0,707 & 0,869 & 0,615 & 0,687 & 0,390 & 1,000 \\
\hline
\end{tabular}

Birbiriyle en yüksek korelasyon katsayılarına sahip değişken eşleşmelerinin sermaye stoku-gelir, sermaye stoku-HT ihracatı, HT ihracatı-gelir değişkenleri arasında olduğu görülmektedir. Değişkenlerin korelasyon katsayıları pozitif, etkileşim terimlerinin katsayıları ise negatiftir.

Bir sonraki adımda sıradan en küçük kareler varsayımlarının geçerliliği sınanacaktır. Regresyon artıklarına uygulanacak testlerin ve ilerleyen aşamada katsayı yorumlarının hangi modelleri referans alınarak yapılacağını belirleyebilmek için model seçimine ihtiyaç duyulmaktadır. Bu amaçla Breusch-Pagan LM ve 
Hausman model spesifikasyon testi gerçekleştirilmiştir. İlgili test istatistikleri izleyen tabloda sunulmuştur.

Tablo 7: Model Belirleme Testleri

\begin{tabular}{|l|c|c|c|c|}
\hline \multirow{2}{*}{ Test Tipi } & \multicolumn{2}{|c|}{ Model 1 (Cobb-Douglas) } & \multicolumn{2}{c|}{ Model 2 (Translog) } \\
\cline { 2 - 5 } & $\begin{array}{c}\text { Test } \\
\text { İstatistiği }\end{array}$ & $\begin{array}{c}\text { Olasılık } \\
\text { Değeri }\end{array}$ & $\begin{array}{c}\text { Test } \\
\text { Istatistiği }\end{array}$ & $\begin{array}{c}\text { Olasılık } \\
\text { Değeri }\end{array}$ \\
\hline Breusch-Pagan LM & 14000,45 & 0,0000 & 13248,10 & 0,0000 \\
\hline Hausmann & 5,22 & 0,1565 & 0,43 & 1,0000 \\
\hline
\end{tabular}

Not: Hausman testi boş hipotez $\mathrm{H}_{0}$ : Katsayılar arasındaki fark sistematik değildir. (Rassal etki modeli uygundur). LM testi boş hipotez $\mathrm{H}_{0}$ : Panel etki yok (Havuzlanmış SEK Uygun)

LM testi bulgularına göre boş hipotez "panel etki yok" reddedilmektedir. Bu doğrultuda rassal etkiler modeli havuzlanmış modele tercih edilmektedir. Hausman test istatistiklerinden elde edilen bulgulara göre her iki model için boş hipotezin ret edilemediği rassal etkiler modelinin uygun olduğu görülmektedir. Bu noktadan hareketle rassal etkiler modelinden elde edilen artıklar için regresyon varsayımlarının geçerliliği (Değişen Varyans, Otokorelasyon, Yatay Kesit Bağımlılığı) test edilecektir. Bu amaçla gerçekleştirilen tanı testlerine ait bulgular Tablo 8'de sunulmuştur.

Tablo 8: Rassal Etkiler Modeli Artıklarına Tanı Testleri

\begin{tabular}{|l|l|c|c|c|c|}
\hline \multirow{2}{*}{ Test } & \multirow{2}{*}{ Test Tipi } & \multicolumn{2}{|c|}{ Model 1 (Cobb-Douglas) } & \multicolumn{2}{c|}{ Model 2 (Translog) } \\
\cline { 3 - 6 } & & $\begin{array}{c}\text { Test } \\
\text { Istatistiği }\end{array}$ & $\begin{array}{c}\text { Olasılık } \\
\text { Değeri }\end{array}$ & $\begin{array}{c}\text { Test } \\
\text { istatistiği }\end{array}$ & $\begin{array}{c}\text { Olasılık } \\
\text { Değeri }\end{array}$ \\
\hline $\begin{array}{l}\text { Değişen } \\
\text { Varyans }\end{array}$ & LR & 1614,19 & 0,0000 & 1599,77 & 0,0000 \\
\hline \multirow{2}{*}{ Otokorelasyon } & $\begin{array}{l}\text { Uyarlanmış } \\
\text { Durbin-Watson }\end{array}$ & 0,1580 & - & 0,1841 & - \\
\cline { 2 - 6 } & Baltagi-Wu LBI & 0,3065 & - & 0,3338 & - \\
\hline $\begin{array}{l}\text { Yatay Kesit } \\
\text { Bağımlık }\end{array}$ & CD & 9,09 & 0,0000 & 6,78 & 0,0000 \\
\hline
\end{tabular}

Değişen varyans testlerinden elde edilen bulgular her iki model için de "Değişen Varyans Yok" boş hipotezi reddedilmesi gerektiğini ve regresyon artıkları varyansının sabit olmadığını göstermektedir. 
Regresyon artıklarında ardışık ilişkinin (otokorelasyon) varlığı ise uyarlanmış Durbin ve Watson (1950) ve Baltagi ve Wu (1999) LBI (locally best invariant) istatistikleriyle araştııılmıştır. Baltagi ve Wu (1999) tarafından önerilen yerel olarak en iyi değişmez (LBI) test istatistiği AR1-GLS rassal etkiler modeli tahminine dayanır. Test istatistiklerinin kritik değer olan 2'den küçük olması boş hipotezin (otokorelasyon yok) her iki model için de ret edildiğini göstermektedir (Kögel, 2004; Castro ve Camarillo, 2014). Bulgular, hata terimlerinin birbiriyle ardışık ilişkili olduğunu, yani referans modelde otokorelasyonun varlığına işaret etmektedir.

Çalışmada oluşturulan veri seti dengesiz panel ve N>T koşullarını taşıdığı için bu kısıtlar altında test istatistikleri üretebilen Pesaran (2004) yatay kesit bağımlılığı analizi gerçekleştirilmiştir. CD test istatistikleri regresyon artıklarında, yatay kesit bağımlılı̆̆ yoktur boş hipotezinin \%1 anlamlılık düzeyinde ret edildiğini işaret etmektedir. Buna göre her iki model de yatay kesit bağımlılık problemi içermektedir. Bu durumda yatay kesit bağımlılığı altında dirençli test istatistikleri hesaplanmasına olanak veren tahmincilerin kullanılması gerekmektedir.

Durağan olmayan serilerle regresyon analizleri gerçekleştirilmesi durumunda sahte istatistikler ve katsayı tahminleri elde edilmesi olasılık dahilindedir. Eğer seriler durağan değil ise birinci farklarla analizlerin gerçekleştirilmesi veya değişkenlerin eş bütünleşik olduğunun ispatlanması gerekir. Çalışmada kullanılan değişkenler sabit terim ve trend eğilimli olarak durağanlık sınamasına tabi tutulmuştur. Tablo 9, ikinci nesil Pesaran (2003) CADF panel birim kök test sonuçlarını vermektedir. 
Tablo 9: Durağanlık Analizi

\begin{tabular}{|c|c|c|c|c|}
\hline \multicolumn{5}{|c|}{ Panel A: Düzeyde CADF İstatistikleri } \\
\hline \multirow{2}{*}{ Değişkenler } & \multicolumn{2}{|c|}{ Sabit } & \multicolumn{2}{|c|}{ Sabit+Trend } \\
\hline & $Z$ [t-bar] & Olasılık & Z [t-bar] & Olasılık \\
\hline $\ln (y)$ & 0,104 & 0,542 & 4,628 & 1,000 \\
\hline $\ln (\mathrm{k})$ & $-1,397$ & $0,081^{*}$ & 2,928 & 0,998 \\
\hline $\ln (\mathrm{h})$ & $-1,479$ & $0,070 *$ & 2,298 & 0,989 \\
\hline $\ln (\mathrm{ht})$ & 0,030 & 0,512 & 3,542 & 1,000 \\
\hline $\ln (k) \ln (h)$ & 1,350 & $0,088^{*}$ & 3,296 & 1,000 \\
\hline $\ln (k) \ln (h t)$ & 2,472 & 0,993 & 7,232 & 1,000 \\
\hline $\ln (\mathrm{h}) \ln (\mathrm{ht})$ & 1,107 & 0,866 & 2,727 & 0,997 \\
\hline$(\operatorname{lnk})^{2}$ & 0,050 & 0,520 & 1,829 & 0,966 \\
\hline$(\operatorname{lnh})^{2}$ & $-0,765$ & 0,222 & 0,118 & 0,453 \\
\hline$(\operatorname{lnh} t)^{2}$ & 0,497 & 0,690 & 4,513 & 1,000 \\
\hline \multicolumn{5}{|c|}{ Panel B: Birinci Fark $(\Delta)$ CADF İstatistikleri } \\
\hline$\Delta \ln (\mathrm{y})$ & $-6,002$ & $0,000 * * *$ & $-5,741$ & $0,000 * * *$ \\
\hline$\Delta \ln (\mathrm{k})$ & $-3,332$ & $0,000 * * *$ & 2,470 & $0,007 * * *$ \\
\hline$\Delta \ln (\mathrm{h})$ & 5,059 & $0,000 * * \star$ & 1,569 & $0,058^{*}$ \\
\hline$\Delta \ln (\mathrm{ht})$ & $-4,757$ & $0,000 * \star \star *$ & $-1,498$ & $0,067^{*}$ \\
\hline$\Delta \ln (\mathrm{k}) \ln (\mathrm{h})$ & $-5,173$ & $0,000 * \star \star$ & 3,511 & $0,000 * \star *$ \\
\hline$\Delta \ln (\mathrm{k}) \ln (\mathrm{ht})$ & $-2,897$ & $0,002^{* * *}$ & $-4,771$ & $0,000 * * *$ \\
\hline$\Delta \ln (h) \ln (h t)$ & $-5,727$ & $0,000 * \star \star$ & 1,661 & $0,048^{* \star}$ \\
\hline$\Delta(\ln k)^{2}$ & $-3,622$ & $0,000 * * *$ & $-1,522$ & $0,064^{*}$ \\
\hline$\Delta(\operatorname{lnh})^{2}$ & $-4,690$ & $0,000 * \star \star$ & $-2,206$ & $0,014^{\star \star}$ \\
\hline$\Delta(\operatorname{lnht})^{2}$ & $-6,300$ & $0,000 * * *$ & $-5,106$ & $0,000 * * *$ \\
\hline
\end{tabular}

Not: ${ }^{(* *)}$ boş hipotezin \% 1 seviyesinde reddedildiğini göstermektedir. Sabit terim kritik değerler: \%10:-2,040 \%5:-2,110, $\% 1:-2,230$. Sabit terim + trend kritik değerler: \%10: $-2,540, \% 5:-2,610, \% 1:-2,730$. Dengesiz panel verilerde sadece t-bar istatistiği yerine standardize edilmiş Z-bar istatistiği hesaplanabilir.

Bulgular, tüm değişkenlerin $\% 5$ anlamlılık seviyesinde hem sabit terim hem de trendli opsiyonlarında düzeyde birim kök içerdiğini işaret etmektedir. Değişkenlerin ancak ilk farklarında durağan hale gelmesi serilerin I(1) olduğunu göstermektedir. Bu nedenle düzeyde analiz yapabilmek ancak eşbütünleşme ilişkisinin (serilerin uzun dönemde birlikte hareket etmesi) ispatlanmasıyla mümkündür.

En iyi doğrusal sapmasız tahmin (BLUE) varsayımlarının araştıııldığı test bulguları neticesinde referans model olan rassal etkiler artıklarında otokorelasyon, değişen varyans ve yatay kesit bağımlılı̆̆ problemlerinin varlığı tespit edilmiştir. Bu durum söz konusu problemlere dirençli regresyon tahminleri yapılmasını 
gerektirmektedir. Referans modelde SEK varsayımlarının karşılanamaması nedeniyle söz konusu problemlerin varlığında dirençli standart hatalar üreten Driscoll-Kraay yöntemiyle regresyon katsayıları tahmin edilmiştir. Elde edilen istatistikler Tablo 10'da sunulmaktadır.

Tablo 10: Driscoll-Kraay Dirençli Standart Hatalarla Regresyon Katsayıları

\begin{tabular}{|c|c|c|c|c|c|c|}
\hline \multirow[b]{2}{*}{ Değişkenler } & \multicolumn{3}{|c|}{ Model 1 (Cobb-Dougles) D-K RE } & \multicolumn{3}{|c|}{ Model 2 (Translog) D-K RE } \\
\hline & Katsayılar & $\begin{array}{c}\text { D-K } \\
\text { Std. Ht. }\end{array}$ & Güven Aralığı & Katsayılar & $\begin{array}{c}\text { D-K } \\
\text { Std. Ht. }\end{array}$ & Güven Aralığı \\
\hline $\ln (k)$ & $0,657 * \star *$ & 0,019 & $0,618 / 0,697$ & $0,649 * \star \star$ & 0,024 & $0,600 / 0,699$ \\
\hline $\ln (\mathrm{h})$ & $0,430 * * *$ & 0,061 & $0,305 / 0,554$ & $0,396^{* * *}$ & 0,042 & $0,310 / 0,482$ \\
\hline $\ln (\mathrm{ht})$ & 0,058 *** & 0,007 & $0,044 / 0,072$ & $0,086^{* * *}$ & 0,007 & $0,070 / 0,101$ \\
\hline $\ln (k) \ln (h)$ & & & & $0.229 * \star \star$ & 0,055 & $0,117 / 0,340$ \\
\hline $\ln (k) \ln (h t)$ & & & & $-0.018^{* * *}$ & 0,006 & $\begin{array}{c}-0,030 /- \\
0,006 \\
\end{array}$ \\
\hline $\ln (\mathrm{h}) \ln (\mathrm{ht})$ & & & & $-0.145^{\star * \star}$ & 0,023 & $-0,193 /-0,098$ \\
\hline$(\operatorname{lnk})^{2}$ & & & & 0,016 & 0,022 & $-0,029 / 0,062$ \\
\hline$(\operatorname{lnh})^{2}$ & & & & $3,655^{\star \star \star}$ & 0,462 & $2,710 / 4,600$ \\
\hline$(\operatorname{lnht})^{2}$ & & & & $0,015^{\star \star *}$ & 0,002 & $0,010 / 0,020$ \\
\hline Sabit Terim & 0,054 & 0,089 & $-0,128 / 0,236$ & 0,030 & 0,079 & $-0,131 / 0,191$ \\
\hline Ki-Kare & $12454,00^{* * *}$ & & & $39328,47^{* * *}$ & & \\
\hline VIF & 1,74 & & & 9,13 & & \\
\hline RMSE & 0,245 & & & 0,252 & & \\
\hline $\mathrm{R}^{2}$ & 0,834 & & & 0,826 & & \\
\hline Gözlem & 1386 & & & 1386 & & \\
\hline Grup & 49 & & & 49 & & \\
\hline $\begin{array}{l}\text { Artık } \\
\text { CADF Testi }\end{array}$ & $\begin{array}{c}-2,362^{* * *} \\
{[0,009]}\end{array}$ & & & $\begin{array}{c}-1.765^{* *} \\
{[0,039]}\end{array}$ & & \\
\hline
\end{tabular}

Not: Parantez Iç̧indeki Değerler Driscoll-Kraay Standart Hatalardır. Katsayılar, standart hatalara bölünerek "t" değerleri elde edilebilir. Köşeli parantez içerisindeki değerler Peseran CADF birim kök testinin olasılık değerlerini göstermektedir. $* * * p<0,01, * * p<0,05,{ }^{*} p<0,1$.

Ilk olarak modellerden elde edilen $\chi^{2}$ istatistikleri modellerin genel olarak anlamlı olduğunu ve model spesifikasyon hatası yapılmadığını işaret etmektedir. Açıklayıcı değişkenlerin bağımlı değişkendeki varyansı açıklama gücü olarak $\mathrm{R}^{2}$ düzeyleri 0,83-0,89 değerleri arasında değişmektedir. Bununla birlikte, her iki modelden elde edilen katsayı büyüklükleri ve işaretleri birbiriyle tutarlı ve aynı işaretlere sahiptir.

Ayrıca, çoklu doğrusal bağlantı problemine karşı VIF değerleri hesaplanmıştır. Elde edilen VIF değerleri Model 1=1,74<10 ve Model $2=9,13<10$ olduğu için 
değişkenler arasında çoklu doğrusal bağlantı problemi yoktur sonucuna ulaşılmıştır. Çoklu doğrusal bağlantıdan şüphelenilmesi gereken eşik VIF değerleri birçok çalışmada 10 olarak belirtilmektedir (Neter, vd., 1996; Kennedy, 2008). Translog modelinde değişkenlerin etkileşim terimleri yer aldığı için VIF değeri artış göstermiş ancak çoklu doğrusal bağlantının varlığını işaret edecek eşik değere ulaşmadığı görülmüştür. Çalışmada değişkenler normalize edildiği ve VIF değerleri kritik düzeyi aşmadığı için Ridge regresyon kullanmak yerine Driscoll-Kraay (1998) standart hatalarla OLS prosedürü uygulanmaktadır.

Bununla birlikte regresyon artıklarına yapılan durağanlık analizi \%5 önem seviyesinde dahi artıkların durağan olduğunu göstermektedir. Bu bulgu tahmin edilen regresyon katsayılarının sahte olmadığını ve elde edilen istatistiklerin güvenle yorumlanabileceğini işaret etmektedir. Serilerin eş bütünleşik olması nedeniyle yapılacak regresyon analizleri uzun dönemde yorumlanabilecektir ve sahte regresyon olasılığından söz edilemez. Katsayıların güven aralığı tahminlerinde değerlerin sabit terim hariç işaret değiştirmemesi açıklayıcı değişkenlerin bağımlı değişkeni etkileme yönünün tutarlı olduğunu işaret etmektedir.

Modeller log-log formda olduğu için tahmin edilen genişletilmiş Cobb-Douglas modelinde değişken katsayıları doğrudan çıktı esnekliklerini vermektedir. Çıktı esnekliklerinin toplamından ise ölçeğe göre getiri durumu hesaplanabilir. Söz konusu dönem ve ülkeler için sermayenin çıktı esnekliğinin 0,66; beşeri sermaye çıktı esnekliğinin ise 0,43 olduğu görülmektedir. HT ihracatının çıktı esnekliği ise yaklaşık olarak 0,06 olarak tahmin edilmiştir. Elde edilen bu bulgular Yoo (2008) ve Falk (2009) çalışmalarında ileri sürülen sonuçlarla uyumlu ve onları desteklemektedir. Böylelikle HT ihracatıyla genişletilmiş Cobb-Douglas üretim fonksiyonunda ölçek değeri 1,145 olarak hesaplanmaktadır. Panel genelinde ülkeler ölçeğe göre artan getiri koşullarında faaliyet göstermektedir.

Translog model katsayıları C-D üretim fonksiyonundan elde edilen bulgularla örtüşmekte ve birbirini doğrulamaktadır. C-D üretim fonksiyonunda yaklaşık olarak 0,06 olan HT katsayısı, bu modelde 0,09 düzeyinde tahmin edilmiştir. Ancak translog modelde tahmin edilen katsayılar doğrudan çıktı esnekliklerini 
vermez. Etkileşim terimlerinin işaretleri incelendiğinde fiziki sermaye-beşeri sermaye etkileşiminin pozitif; fiziki sermaye-HT ve beşeri sermaye-HT işaretlerinin negatif olduğu görülmektedir. Bu durum, fiziki sermaye-beşeri sermaye faktörleri arasında tamamlayıcılık; fiziki sermaye-HT ve beşeri sermaye-HT arasında ikame ilişkilerinin olabileceğini işaret etmektedir. Bununla birlikte HT kuadratik terimi de istatistiksel olarak anlamlı ve katsayı işareti pozitiftir.

Sağlamlık kontrolü (robustness check) için yapılan alternatif regresyon tahminlerinden elde edilen bulgular söz konusu tespitleri güçlendirmektedir. Translog modeli için sağlamlık kontrolünden elde edilen katsayı ve istatistikler ekler kısmında sunulmaktadır.

\subsection{Translog Üretim Fonksiyonunda Faktör, Ölçek ve İkame Esnekliklerinin Hesaplanması}

Üç faktörlü bir translog üretim fonksiyonunda çıktı esneklikleri aşağıdaki gibi hesaplanmaktadır.

$$
\begin{aligned}
& \frac{\partial \ln (y)}{\partial \ln (k)}=e_{k}=\beta_{1}+\beta_{4} \ln (h)+\beta_{5} \ln (h t)+\beta_{7} \ln (k) \\
& \frac{\partial \ln (y)}{\partial \ln (h)}=e_{h}=\beta_{2}+\beta_{4} \ln (k)+\beta_{6} \ln (h t)+\beta_{8} \ln (h) \\
& \frac{\partial \ln (y)}{\partial \ln (h t)}=e_{h t}=\beta_{3}+\beta_{5} \ln (k)+\beta_{6} \ln (h)+\beta_{9} \ln (h t)
\end{aligned}
$$

Bireysel çıktı esnekliklerinin toplamı ise ölçeğe göre getiriyi (RTS) vermektedir.

$$
R T S=e_{k}+e_{h}+e_{h t}
$$

Translog üretim fonksiyonunda çıktı esnekliklerinden hareketle ikame esnekliğinin hesaplanması Denklem 17'de gösterilmektedir. 


$$
\begin{aligned}
& s_{k-h}=|1+|-\beta_{4}+\left(\frac{e_{k}}{e_{h}}\right) \beta_{8}\left|\left(-e_{k}+e_{h}\right)^{-1}\right|^{-1} k-h \text { ikame esnekliği } \\
& s_{k-h t}=|1+|-\beta_{5}+\left(\frac{e_{k}}{e_{h t}}\right) \beta_{9}\left|\left(-e_{k}+e_{h t}\right)^{-1}\right|^{-1} k-h t \text { ikame esnekliğ } i \\
& s_{h-h t}=|1+|-\beta_{6}+\left(\frac{e_{h}}{e_{h t}}\right) \beta_{9}\left|\left(-e_{h}+e_{h t}\right)^{-1}\right|^{-1} h-h t \text { ikame esnekliğ } i
\end{aligned}
$$

Yukarıdaki denklemlerden hesaplanan esneklik katsayıları ülke sıralamalarına göre Tablo 11'de verilmektedir.

Tablo 11: Esneklik Katsayıları

\begin{tabular}{|l|c|c|c|c|c|c|c|c|}
\hline Ülke & $e_{k}$ & $e_{h}$ & $e_{h t}$ & $R T S$ & $s_{k-h}$ & $s_{k-h t}$ & $S_{h-h t}$ & Sıra \\
\hline Güney Kore & 0,710 & 1,378 & 0,050 & 2,139 & 0,288 & 1,523 & 1,706 & 1 \\
\hline Hong Kong & 0,720 & 1,362 & 0,034 & 2,117 & 0,274 & 1,931 & 2,246 & 2 \\
\hline Rusya & 0,739 & 1,305 & 0,019 & 2,063 & 0,235 & 5,781 & 10,622 & 3 \\
\hline Şili & 0,741 & 1,225 & 0,020 & 1,985 & 0,196 & 4,760 & 8,143 & 4 \\
\hline Güney Afrika & 0,727 & 1,166 & 0,031 & 1,924 & 0,177 & 2,113 & 2,636 & 5 \\
\hline Avustralya & 0,715 & 1,128 & 0,036 & 1,880 & 0,165 & 1,824 & 2,223 & 6 \\
\hline Yunanistan & 0,725 & 1,120 & 0,025 & 1,870 & 0,156 & 2,713 & 3,712 & 7 \\
\hline A.B.D & 0,703 & 1,117 & 0,047 & 1,867 & 0,167 & 1,564 & 1,851 & 8 \\
\hline Polonya & 0,710 & 1,107 & 0,049 & 1,865 & 0,158 & 1,542 & 1,829 & 9 \\
\hline Letonya & 0,711 & 1,061 & 0,039 & 1,811 & 0,136 & 1,746 & 2,151 & 10 \\
\hline Türkiye & 0,637 & 0,258 & 0,086 & 0,981 & 0,045 & 1,298 & 9,652 & 35 \\
\hline İzlanda & 0,661 & 0,232 & 0,070 & 0,964 & 0,044 & 1,360 & 5,056 & 40 \\
\hline Hindistan & 0,662 & 0,222 & 0,075 & 0,959 & 0,043 & 1,335 & 3,483 & 41 \\
\hline Çin & 0,632 & 0,208 & 0,105 & 0,944 & 0,041 & 1,254 & 1,454 & 42 \\
\hline Finlandiya & 0,635 & 0,183 & 0,092 & 0,910 & 0,038 & 1,281 & 1,072 & 43 \\
\hline Danimarka & 0,617 & 0,130 & 0,103 & 0,850 & 0,029 & 1,261 & 0,205 & 44 \\
\hline Portekiz & 0,648 & 0,088 & 0,078 & 0,814 & 0,021 & 1,327 & 0,064 & 45 \\
\hline Endonezya & 0,656 & 0,078 & 0,077 & 0,811 & 0,019 & 1,329 & 0,005 & 46 \\
\hline İspanya & 0,635 & 0,049 & 0,088 & 0,771 & 0,013 & 1,295 & 0,202 & 47 \\
\hline Belçika & 0,619 & 0,037 & 0,101 & 0,758 & 0,010 & 1,264 & 0,296 & 48 \\
\hline Almanya & 0,623 & 0,026 & 0,100 & 0,750 & 0,007 & 1,265 & 0,332 & 49 \\
\hline Ülke Ort. & $\mathbf{0 , 6 6 8}$ & $\mathbf{0 , 5 8 4}$ & $\mathbf{0 , 0 7 1}$ & $\mathbf{1 , 3 2 2}$ & $\mathbf{0 , 0 7 0}$ & $\mathbf{1 , 5 8 2}$ & $\mathbf{3 , 2 4 3}$ & \\
\hline
\end{tabular}

Not: Yazarın kendi hesaplamaları. Ölçeğe göre getiri durumuna göre sıralanmıştır.

Ölçeğe göre artan getiri koşullarına göre ülkeler sıralandığında incelenen dönemde en yüksek getiri koşullarına sahip ilk üç ülkenin Güney Kore, Hong Kong 
ve Rusya olduğu görülmektedir. Hesaplamada ölçeğe göre azalan getiri koşullarında üretim yapan gelişmiş ülkelerin varlı̆̆ı ise dikkat çekicidir. Faktör esneklikleri incelendiğinde bu durumun gelişmiş ülkeler için olası birkaç nedeni bulunmaktadır. Bunlardan ilki durağan duruma yaklaşan gelişmiş̧ülkelerde azalan getiri koşullarının oluşması beklenen bir neticedir. İkinci olarak ise, faktör fiyatlarıyla ilgilidir. Beşeri sermaye ücretlerinin (fiyatlarının) göreli olarak yüksek olduğu ülkelerde üretimde beşeri sermaye yerine diğer faktörler ikame edilebilir.

Ülkeler faaliyette bulunduğu üretim tekniği ve sahip olduğu teknoloji düzeyi gereği bazı ülkelerde faktörler arası ikame esnekliği yüksek iken, bazı ülkelerde düşüktür. Beşeri sermayenin ölçeğe göreli olarak daha az katkı verdiği ülkelerde ikame esneklikleri incelendiğinde fiziki sermaye ve beşeri sermayenin birbiri yerine kolayca ikame edilemediği iki faktör arasında tamamlayıcılık ilişkisinin daha kuvvetli olduğu görülmektedir.

Ölçeğe göre azalan getiri koşullarında çalışan gelişmekte olan ülkelerde beşeri sermayenin ölçeğe düşük katkı vermesinin olası nedeni ise fiziki sermaye ile tamamlanacak eşik değere ulaşamamasıdır. Yani beşeri sermaye stoğu bu ülkelerde eksiktir. Bir diğer olası neden ise beşeri sermaye niteliği ile ilgilidir. Yeterli beşeri sermaye stoğu olması durumunda dahi gelişmekte olan ülkeler gelişmiş ülkelerin nitelik açısından gerisinde olabilmektedir. Eğitim kalitesini ölçen PISA ve benzeri uluslararası sınav sonuçları incelendiğinde aynı eğitim düzeyine sahip gelişmiş ve gelişmekte olan ülkeler arasında nitelik farklılığının olduğu görülmektedir. Ölçeğe göre azalan getiri koşullarında üretim yapan gelişmekte olan ülkeler incelendiğinde üretime en yüksek katkıyı fiziki sermayenin verdiği görülmektedir.

Ülkeler, çıktı esneklikleri açısından fiziki sermaye ve HT faktörlerinde birbirine benzer özellikler sergilemekteyken beşeri sermaye faktöründe önemli değişimler ortaya çıkmaktadır. Panel geneli için de beşeri sermayenin ölçeğe önemli bir katkı verdiği gözlenmektedir. Fiziki sermayenin ölçeğe katkısı olan çıtı esnekliği 0,668; beşeri sermayenin çıktı esnekliği 0,584 ve HT ihracatının çıktı esnekliği 0,071 düzeyinde hesaplanmıştır. 
Türkiye'nin ölçeğe göre getiri sıralamasında 35. sırada yer aldığı; ölçeğin 0,985 değeriyle azalan getiri koşullarında faaliyet gösterdiği ve sabit getiri noktasına yakın olduğu görülmektedir. Çıktı esneklikleri fiziki sermaye için 0,637; beşeri sermaye için 0,258 ve HT ihracatı esnekliği 0,086 düzeyindedir. Türkiye'de HT ihracatının işgücü başına çıktıya verdiği katkı panel ortalamasının üzerindedir. Bu bulgu ülkenin ihracat kompozisyonunu HT ihracatı lehine çeşitlendirecek politika ve yatırımlar yolunu izlemesiyle gelirini anlamlı bir şekilde artırabileceğini göstermektedir. Faktörler arasındaki ikame esnekliği en yüksek olan faktörler beşeri sermaye ve HT ihracatıdır.

Translog modelinde beşeri sermaye $(\operatorname{lnh})^{2}$ ve HT ihracatı $(\operatorname{lnht})^{2}$ kuadratik terimlerinin istatistiksel olarak anlamlı olması söz konusu faktörlerin işgücü başına gelire (lny) doğrusal olmayan bir biçimde katkı verdiğini göstermektedir. Fiziki sermaye (lnk) ve gelir arasındaki ilişki ise doğrusaldır. Regresyon denkleminin faktörlere göre kısmi türevi çıktı esnekliklerini vermekteyken, ikinci mertebeden türevi doğrusal olmayan ilişkinin biçimi hakkında bize bilgi verir. Model logaritmik formda olduğu için fonksiyonun bağımsız değişkenlere göre kısmi türevleri esneklikleri vermektedir. Buradan hareketle esneklik-eğim ilişkisine dayanarak fonksiyonun grafiği hakkında yorum yapılabilir.

$$
\begin{aligned}
& f(k, h, h t) i c ̧ i n ; \\
& f_{h}^{\prime}=\frac{\partial \ln y}{\partial \ln h}=e_{h}=\beta_{2}+\beta_{4} \ln (k)+\beta_{6} \ln (h t)+\beta_{8} \ln (h) \\
& f_{h h}^{\prime \prime}=\frac{\partial^{2} \ln y}{\partial \ln h^{2}}=\beta_{8} \\
& f_{h t}^{\prime}=\frac{\partial \ln y}{\partial \ln h t}=e_{h t}=\beta_{3}+\beta_{5} \ln (k)+\beta_{6} \ln (h)+\beta_{9} \ln (h t) \\
& f_{h t h t}^{\prime \prime}=\frac{\partial^{2} \ln y}{\partial \ln h t^{2}}=\beta_{9}
\end{aligned}
$$

Eğim ve esneklik arasındaki ilişki ise 19 numaralı eşitlikte gösterilmektedir³ .

\footnotetext{
${ }^{3}$ Fonksiyonların geometrik gösterimlerinde yatay eksene bağımsız değişken(x), dikey eksene ise bağımlı değişken(y) yerleştirilerek analiz yapılır. Ancak iktisat disiplininde talep fonksiyonunun grafiksel gösterimi ters talep fonksiyonuna göredir. Yani dikey eksende fiyat, yatay eksende miktar vardır. Bu durum eğim hesaplamalarında karışıklıklara sebep olur. Bu nedenle talep eğrisine özel olarak eğim ve esneklik ilişkisi $e=\frac{1}{m} * \frac{P}{Q}$ şeklindedir.
} 


$$
e=\frac{\Delta Y}{\Delta X} * \frac{X}{Y} \text { ve eğim }(m)=\frac{\Delta Y}{\Delta X} \text { ise } ; e=m * \frac{X}{Y}
$$

Regresyon katsayılarına dayanarak 18 ve 19 numaralı denklemlerden hareketle fonksiyonun ilgili noktalardaki eğim ve esneklik parametreleri hesaplanarak izleyen tabloda verilmiştir.

Tablo 16: Gelir ve Faktörler Arasındaki Fonksiyonel İlişkinin Biçimi

\begin{tabular}{|l|c|c|c|c|}
\hline & \multicolumn{2}{|c|}{ Esneklik } & \multicolumn{2}{c|}{ Eğim } \\
\hline & $f^{\prime}$ & $f^{\prime \prime}$ & $f^{\prime}$ & $f^{\prime \prime}$ \\
\hline Beşeri Sermaye & 0,584 & 3,6668 & 0,0379 & 0,2381 \\
\hline HT İhracatı & 0,071 & 0,0152 & 0,0037 & 0,0008 \\
\hline
\end{tabular}

Tablo 16 incelendiğinde HT ihracatının işgücü başına gelire azalarak artan, beşeri sermayenin ise işgücü başına gelire ise artarak artan bir eğri boyunca katkı verdiği tespit edilmiştir. Fiziki sermaye ve gelir ilişkisinin ise doğrusal olduğu görülmektedir. Şekil 5, HT ihracatı ve işgücü başına gelir arasındaki azalarak artan fonksiyonel ilişkiyi göstermektedir.

Şekil 5. HT İhracatı ve İşgücü Başına Gelir

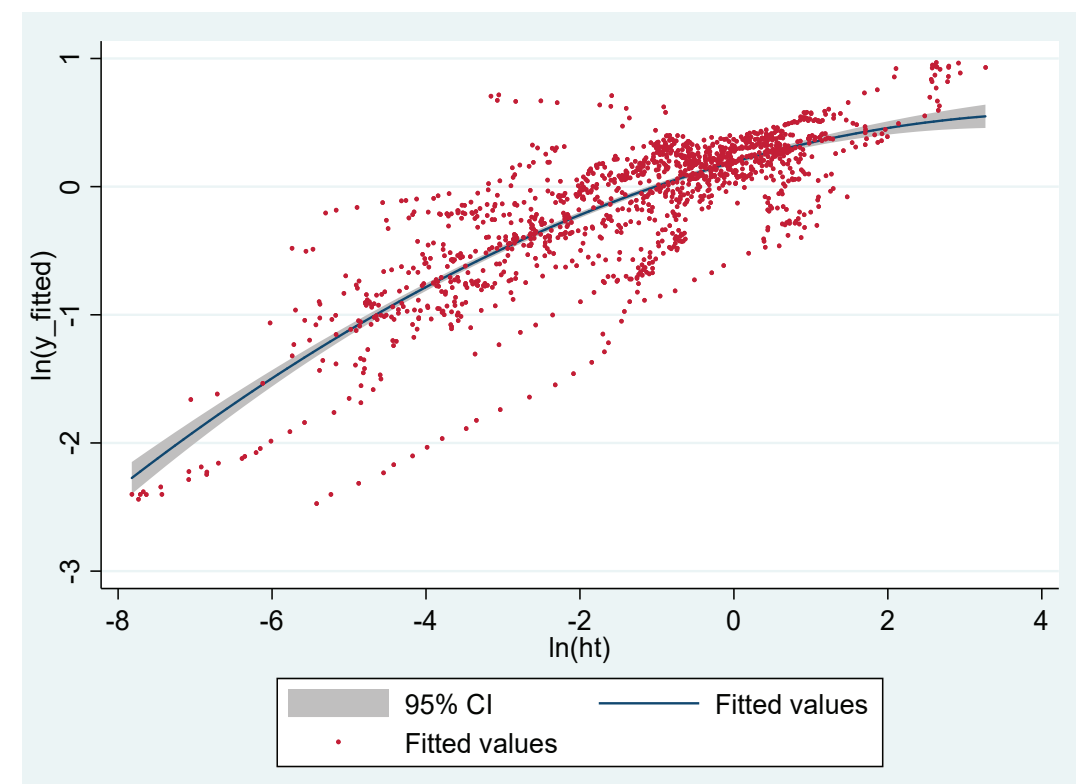


Bulgulara göre, ülkelerin gelir düzeyini fiziki sermayeden daha kuvvetli bir şekilde beşeri sermayenin ve bilgi düzeyinin göstergesi olarak modele dahil edilen HT faktörünün uyardığı söylenebilir. Bu sonuç beşeri sermaye ve teknoloji yoğun ihracatın gelir için oldukça önemli faktörler olduğunu göstermektedir. Ancak beşeri sermaye ve fiziki sermaye arasında tamamlayıcılık ilişkisi olduğu için fiziki sermayeyi beşeri sermayeyi tamamlayacak şekilde artıracak politikalar izlenmelidir.

\section{Sonuç}

Bu çalışma, HT ihracatının gelir üzerindeki etkilerine yönelik tartışmaya orta ve yüksek gelir grubundaki ülkeler ve 1988-2017 döneminden oluşan bir örneklemle iki üretim fonksiyonu özelinde katkı sunmaktadır.

Her iki modelden elde edilen ampirik sonuçlar, yüksek teknoloji ihracatının kişi başına gelir üzerindeki pozitif etkisine dair güçlü kanıtlar sunmaktadır. Bu bulgular ana modellere ek olarak alternatif regresyon yöntemleriyle sağlamlık kontrolünden geçirilmiş ve mevcut modellerle uyumlu neticeler elde edilmiştir.

Cobb-Douglas modelinde; HT ihracatındaki yaşanacak \%1'lik bir artış, işgücü başına gelir düzeyini \% 0,06 kadar artırmaktadır. Fiziki sermayenin çıktı esnekliği 0,657; beşeri sermayenin çıktı esnekliği ise 0,430 olarak hesaplanmıştır. Translog üretim yapısında ise HT ihracatının çıktı esnekliği 0,071 olarak hesaplanmıştır. Bu üretim yapısında diğer faktörlerin çıktı esneklikleri fiziki sermaye için yaklaşık olarak 0,668; beşeri sermayenin ise 0,584 düzeyindedir. İkame esneklikleri incelendiğinde fiziki-beşeri sermayenin ikame ilişkisinin zayıf olduğu ve tamamlayıc faktörler olduğu görülmektedir. Beşeri sermaye-HT; fiziki sermayeHT faktörleri ise birbiri yerine ikame edilebilen faktörlerdir. Bununla birlikte 2 ülkenin (İsveç ve Norveç) ölçeğe göre sabit getiriler, 15 ülkenin ölçeğe göre azalan getiriler ve 32 ülkenin ölçeğe göre artan getiriler altında üretim yaptığı tespit edilmiştir. Panel genelinde ülkeler 1,322 değeriyle ölçeğe göre artan getiriler özelliği sergilemektedir. Fiziki sermayenin toplam çıktıya katkısı ülkeler özelinde benzer düzeylerde (0,602-0,741 arasında) seyretmekteyken, ölçeğe göre artan getirilere geçme koşulunun beşeri sermaye faktörüne dayandığı görülmektedir. 
Beşeri sermaye faktörüne ait bu bulgular MRW (1992) ve ona dayalı olarak üretilen ampirik çalışmalarla örtüşmektedir.

Bunun yanı sıra, HT ihracatıyla ilgili bulgular ihracata dayalı büyüme fenomeninde teknoloji yoğun ihracatın önemini vurgulamaktadır. Bu bulgular translog üretim fonksiyonu için de Yoo (2008), Falk (2009) ve literatür kısmında değinilen birçok çalışmayı desteklemektedir. Uçak, ilaç ve elektronik gibi teknoloji yoğun içeriğe sahip malların ihracatında giderek daha fazla uzmanlaşan ülkeler daha yüksek büyüme oranlarını yakalayacaktır. Sonuçlar, özellikle zengin / gelişmiş ülkelerin yüksek teknoloji ihracatı odaklı daha fazla katma değerli ürün ihraç etmeleri gerektiği hipoteziyle de uyuşmaktadır.

Ayrıca HT ihracatının işgücü başına gelire azalarak artan, beşeri sermayenin ise işgücü başına gelire ise artarak artan bir eğri boyunca katkı verdiği tespit edilmiştir. Fiziki sermaye ve gelir ilişkisinin ise doğrusal olduğu saptanmıştır.

Bu nedenlerle, HT ihracatı odaklı teknoloji yoğun alanda uygulanacak politikalar gelire pozitif katkı verecektir. Söz konusu makro iktisadi değişkenlerin yanı sıra temel bilimlerin desteklenmesi, yeni teknolojilerin gelişimini kolaylaştıracak kurumsal düzenlemelerin yapılması, uzun dönemde HT ihracatı payını artırmak için iyi bir yol gibi görünmektedir.

Ayrıca belirtmek gerekir ki, HT ihracatının gelire katkı verebilmesi doğal olarak serbest ticaret rejimine sahip ülkeler için geçerlidir. Teknoloji yoğun ticaret, daha az gelişmiş ülkelerin yerel inovasyonu artırabilecekleri ve gelişmiş yabancı teknolojileri kullanılabilecekleri bir mekanizmadır. Buna uygun olarak HT ihracatını desteklemek için teknoloji yoğun serbest bölgelerin kurulması, bu bölgelerin lojistik altyapısının da sağlanması gerekir. Başka bir çalışmada Şanlı (2019), OECD ülkeleri için HT yoğun ürünlerin diğer teknoloji gruplarına göre daha çok enerji tüketimi gerçekleştirdiği ve enerji tüketimi-HT ihracatı arasında geri besleme ilişkisinin varlığını vurgulamaktadır. Bu bağlamda enerji arzı sürekliliğinin sağlanması HT ihracatını destekleyecektir ve bu yeni enerji yatırımlarıyla mümkün görünmektedir. 
Beşeri sermayenin gelire doğrusal olmayan biçimde artarak artan bir eğri boyunca katkı vermesi bu faktörün ülkeler açısından önemini vurgulamaktadır. Beşeri sermayenin bu özelliği yanı sıra ölçeğe göre artan getiriler koşulunun belirleyicisi ve geliri belirleyen baskın faktör olması nedeniyle orta gelir tuzağından çıkmak için ülkelere salık verilen yüksek teknoloji ihracatını artırma politikalarının aslında beşeri sermayeyi tamamlayan destekleyici bir unsur olabileceğini göstermektedir. Bu nedenlerle gelişmekte olan ülkelerin orta gelir tuzağına düşmemek veya bu eşiği aşabilmek için önce beşeri sermayenin nitelik ve niceliğini artıracak politikalara odaklanmalıdır. İşgücü başına geliri beşeri sermaye kanalıyla artırmanın ise temel iki yolu bulunmaktadır. Bunlardan ilki eğitim politikaları bir diğeri ise sağlık politikalarıdır. Beşeri sermaye öncelikle eğitim düzeyi ile ölçüldüğü için ortalama eğitim yılını artıracak politikalar izlenmelidir. Gelişmiş ve gelişmekte olan ülkeler arasındaki eğitim açığı ise sadece ortalama eğitim yılının farklılaşmasından değil bununla birlikte eğitimin kalitesinin farklılaşmasından da kaynaklanmaktadır. Aynı zamanda ortalama eğitim yılı bir cinsiyet eşitsizliği de barındırmaktadır. Özellikle gelişmekte olan ülkelerde kadınların hem eğitim yılı hem de buna paralel olarak işgücüne katılımı nispeten düşüktür. Bu doğrultuda temel olarak eğitim düzeyinin niceliğini ve niteliğini artıracak politikalar hem gelir artışını uyaracak hem de cinsiyet eşitsizliği gibi sosyal sorunların azalmasına katkı sunacaktır.

\footnotetext{
Etik Komite Onayı: Çalışma etik kurul onayı gerektirmemektedir.

Hakem Değerlendirmesi: Dış bağımsız.

Yazar Katkıları: Çalışma Konsepti/Tasarım- D.Ş., A.K.; Veri Toplama- D.Ş.; Veri Analizi/Yorumlama- D.Ş., A.K.; Yazı TaslağıD.Ş.; İçeriğin Eleştirel İncelemesi- A.K.; Son Onay ve Sorumluluk- D.Ş., A.K.

Çıkar Çatışması: Yazar çıkar çatışması bildirmemiştir.

Finansal Destek: Yazar bu çalışma için finansal destek almadığını beyan etmiştir.
}

Ethics Committee Approval: The study does not require ethics committee approval.

Peer-review: Externally peer-reviewed.

Author Contributions: Conception/Design of Study- D.Ş., A.K.; Data Acquisition- D.Ş.; Data Analysis/Interpretation- D.Ş., A.K.; Drafting Manuscript- D.Ş.; Critical Revision of Manuscript- A.K.; Final Approval and Accountability- D.Ş., A.K. Conflict of Interest: The author has no conflict of interest to declare.

Grant Support: The author declared that this study has received no financial support. 


\section{Kaynaklar/References}

Aghion, Ph. \& Howitt, P. (1998). Endogenous growth theory. USA: MIT Press

Aiginger, K. \& Falk, M. (2005). Explaining differences in economic growth among OECD countries. Empirica, 32(1), 19-43.

Amable, B. (2000). International specialisation and growth. Structural change and economic dynamics, 11(4), 413-431.

Arrow, K. J., Chenery, H. B., Minhas, B. S. \& Solow, R. M. (1961). Capital-labor substitution and economic efficiency. The review of Economics and Statistics, 225-250.

Avila-Lopez, L. A., Lyu, C. \& Lopez-Leyva, S. (2019). Innovation and growth: Evidence from Latin American countries. Journal of Applied Economics, 22(1), 287-303.

Bal, H., Çiftçi, H., İşcan, E. \& Serin, D. (2016). İhracata dayalı büyüme: Teknolojik bakış The export-led growth: A technological view. In International Conference on Eurasian Economies. 311-316.

Baltagi, B. H. \& Wu, P. X. (1999). Unequally spaced panel data regressions with AR (1) disturbances. Econometric Theory, 814-823

Barro, R. J. \& Lee, J. W. (2013). A new data set of educational attainment in the world, 19502010. Journal of Development Economics, 104, 184-198. Erişim: http://www.barrolee.com/.

Berndt, E. R. \& Christensen, L. R. (1973). The translog function and the substitution of equipment, structures, and labor in US manufacturing 1929-68. Journal of Econometrics, 1(1), 81-113.

Bosworth, B. \& Collins, S. M. (2003). The empirics of growth: An update. Brookings Papers on Economic Activity, 2003(2), 113-206.

Carrasco, C. A. \& Tovar-García, E. D. (2020). Trade and growth in developing countries: the role of export composition, import composition and export diversification. Economic Change and Restructuring, 1-23.

Castro, G. Á. \& Camarillo, D. B. R. (2014). Determinants of tax revenue in OECD countries over the period 2001-2011. Contaduría y Administración, 59(3), 35-59.

Chrid, N., Saafi, S. \& Chakroun, M. (2020). Export upgrading and economic growth: A panel cointegration and causality analysis. Journal of the Knowledge Economy, 1-31.

Christensen, L. R., Jorgenson, D. W. \& Lau, L. J. (1973). Transcendental logarithmic production frontiers. The Review of Economics and Statistics, 55(1), 28-45.

Cobb, C. W. \& Douglas, P. H. (1928). A theory of production. The American Economic Review, 18(1), 139-165.

Coe, D. T. \& Helpman, E. (1995). International R\&D spillovers. European Economic Review, 39(5), 859-887.

Cohen, D., Leker, L. \& Soto, M. (2014). International educational attainment database. Erişim: http:// www.parisschoolofeconomics.eu/en/cohen-daniel/international-educational-attainment-database/

Cuaresma, J. C. \& Wörz, J. (2005). On export composition and growth. Review of World Economics, 141(1), 33-49.

Debertin, D. L. (2012). Agricultural production economics (2nd. ed.), USA: Pearson. 
Driscoll, J. C. \& Kraay, A. C. (1998). Consistent covariance matrix estimation with spatially dependent panel data. Review of Economics and Statistics, 80(4), 549-560.

Du, K. (2017). Translog: Stata module to create new variables for a translog function. Statistical Software Components S458318. Erişim: https://ideas.repec.org/c/boc/bocode/s458318.html

Durbin, J., \& Watson, G. S. (1950). Testing for serial correlation in least squares regression: I. Biometrika, 37(3/4), 409-428.

Ekananda, M. \& Parlinggoman, D. J. (2017). The role of high-tech exports and of foreign direct investments ( $\mathrm{fd}_{\mathrm{l}}$ ) on economic growth. European Research Studies Journal, 20(4A), 194-212.

Erkişi, K. \& Boğa, S. (2019). High-techonology products export and economic growth: A panel data analysis for EU-15 countries. Bingöl Üniversitesi Sosyal Bilimler Enstitüsü Dergisi, 9(18), 669-684.

Fagerberg, J., Srholec, M. \& Knell, M. (2007). The competitiveness of nations: Why some countries prosper while others fall behind. World Development, 35(10), 1595-1620.

Falk, M. (2007). R\&D spending in the high-tech sector and economic growth. Research in Economics, 61(3), 140-147.

Falk, M. (2009). High-tech exports and economic growth in industrialized countries. Applied Economics Letters, 16(10), 1025-1028.

Fang, C., Kuo, K. H. \& Lee, C. T. (2019). Free trade and economic growth: The role of talent diversity. Bulletin of Economic Research, 72(1), 1-13.

Feder, G. (1983). On exports and economic growth. Journal of Development Economics, 12(1-2), 59-73.

Gani, A. (2009). Technological achievement, high technology exports and growth. Journal of Comparative International Management, 12(2), 31-47.

Geary, R. C. (1950). A note on "A constant-utility index of the cost of living". The Review of Economic Studies, 18(1), 65-66.

Harberger, A. (1978), Perspectives on capital and technology in less developed countries. In M.J. Artis \& A.R. Nobey (Eds.), Contemporary Economic Analysis London: Croom Helm.

Herzer, D. \& Nowak-Lehmann D, F. (2006). Export diversification, externalities and growth: Evidence for Chile. In Proceedings of the German Development Economics Conference, Berlin 2006 (No. 12).

Işık, N. ve Kılınç, E. C. (2016). İnovasyon-temelli ekonomi: seçilmiş ülkeler üzerine bir uygulama. Anadolu Üniversitesi Sosyal Bilimler Dergisi, 16(1), 13-27.

Jaccard, J. \& Turrisi, R. (2003). Interaction effects in multiple regression. SAGE Publications.

Jarreau, J. \& Poncet, S. (2012). Export sophistication and economic growth: Evidence from China. Journal of Development Economics, 97(2), 281-292.

Kalaitzi, A. S. \& Chamberlain, T. W. (2020). The validity of the export-led growth hypothesis: some evidence from the GCC. The Journal of International Trade \& Economic Development, 1-22.

Kennedy, P. (2008). A guide to econometrics, Oxford. Willey Blackwell.

Kılavuz, E., \& Altay Topçu, B. (2012). Export and economic growth in the case of the manufacturing industry: panel data analysis of developing countries. International Journal of Economics and Financial Issues, 2(2), 201-215. 
Kim, D. S. (1999). A standardization technique to reduce the problem of multicollinearity in polynomial regression analysis. Erişim: http://citeseerx.ist.psu.edu/viewdoc/ download?doi=10.1.1.573.1999\&rep=rep1\&type =pdf.

Kim, H. Y. (1992). The translog production function and variable returns to scale. The Review of Economics and Statistics, 546-552.

Kim, M. (2019). Cross-industry distribution of R\&D investments and economic growth. Applied Economics Letters, 27(8), 679-684.

Kmenta,J. (1967). On estimation of the ces production function. International Economic Review, 8(2), 180-189.

Kögel, T. (2004). Did the association between fertility and female employment within OECD countries really change its sign? Journal of Population Economics, 17(1), 45-65.

Kumbhakar, S. C., Lien, G. \& Hardaker, J. B. (2014). Technical efficiency in competing panel data models: a study of Norwegian grain farming. Journal of Productivity Analysis, 41(2), 321-337.

Kumbhakar, S. C., Wang, H. J. \& Horncastle, A. P. (2015). A practitioner's guide to stochastic frontier analysis using Stata. Cambridge University Press.

Lee,J. (2011). Export specialization and economic growth around the world. Economic systems, 35(1), 45-63. Leontief, W. W. (1941). The structure of the american economy 1919-1929. Harvard University Press,

Lin, B. \& Ahmad, I. (2016). Technical change, inter-factor and inter-fuel substitution possibilities in Pakistan: a trans-log production function approach. Journal of Cleaner Production, 126, 537-549

Lin, B. \& Xie, C. (2014). Energy substitution effect on transport industry of China-based on trans-log production function. Energy, 67, 213-222.

Lucas Jr, R. E. (1988). On the mechanics of economic development. Journal of Monetary Economics, 22(1), 3-42.

Madsen, J. B. (2007). Technology spillover through trade and TFP convergence: 135 years of evidence for the OECD countries. Journal of International Economics, 72(2), 464-480.

Mankiw, N. G., Romer, D. \& Weil, D. N. (1992). A contribution to the empirics of economic growth. The Quarterly Journal of Economics, 107(2), 407-437.

Markandya, A. \& Pedroso-Galinato, S. (2007). How substitutable is natural capital? Environmental and Resource Economics, 37(1), 297-312.

Miller, E. (2008). An assessment of CES and Cobb-Douglas production functions (pp. 2008-2005). Washington, DC: Congressional Budget Office.

Minondo, A. (2010). Exports' productivity and growth across Spanish regions. Regional Studies, 44(5), 569-577. Morishima, M. (1963). Equilibrium, stability and growth: A multi-sectoral analysis. Oxford University Press.

Naude, W., Bosker, M. \& Matthee, M. (2010). Export specialisation and local economic growth. World Economy, 33(4), 552-572.

Neter, J. M. H. Kutner, C. J. Nachtsheim \& W. Wasserman. (1996). Applied linear statistical models. USA: Irwin.

Nguyen, L. P. \& Pham, V.H.T. (2020). Trade of ict products, government, and economic growth: Evidence from east asia-pacific region. The Journal of Asian Finance, Economics and Business (JAFEB), 7(8), 175-183. 
O'Brien, R. M. (2007). A caution regarding rules of thumb for variance inflation factors. Quality \& Quantity, 41(5), 673-690.

Orviská, M., Huňady, J., Pisár, P. \& Hudson, J. (2019). From academic publications and patents to the technological development of the economy: Short and long run causalities. Quality Innovation Prosperity, 23(1), 74- 101.

Ostbye, S. (2010). The translog growth model. Journal of Macroeconomics, 32(2), 635-640.

Pablo-Romero, M. D. P. \& Gómez-Calero, M. D. L. P. (2013). A translog production function for the spanish provinces: Impact of the human and physical capital in economic growth. Economic Modelling, 32, 77-87.

Pablo-Romero, M. D. P. \& Sánchez-Braza, A. (2017). Residential energy environmental Kuznets curve in the EU-28. Energy, 125, 44-54.

Pablo-Romero, M. D. P., Sánchez-Braza, A. \& Expósito, A. (2019). Industry level production functions and energy use in 12 EU countries. Journal of Cleaner Production, 212, 880-892.

Paroush, J. (1966). The h-homogeneous production function with constant elasticity of substitution: A note. Econometrica, 34(1), 225-227.

Peneder, M. (2003). Industrial structure and aggregate growth. Structural Change and Economic Dynamics, 14(4), 427-448.

Pesaran, M. H. (2003). A simple panel unit root test in the presence of cross section dependence (No. 0346). Faculty of Economics, University of Cambridge.

Pesaran, M. H. (2004). General diagnostic tests for cross section dependence in panels (No. 1240). IZA Discussion Paper.

Plümper, T. \& Graff, M. (2001). Export specialization and economic growth. Review of International Political Economy, 8(4), 661-688.

Revankar, N. S. (1971). A class of variable elasticity of substitution production functions. Econometrica: Journal of the Econometric Society, 61-71.

Ribeiro, A. P., Carvalho, V. \& Santos, P. (2016). Export-led growth in the EU: Where and what to export? The International Trade Journal, 30(4), 319-344.

Romer, P. M. (1986). Increasing returns and long-run growth. Journal of Political Economy, 94(5), 1002-1037.

Santos, P. G., Ribeiro, A. P. \& Carvalho, V. M. (2013). Export-led growth in Europe: Where and what to export? FEP Working papers No, 479.

Satrovic, E. (2018). Economic output and high-technology export: Panel causality analysis. Uluslararası Ekonomik Araştırmalar Dergisi, 4(3), 55-63.

Shacham, M. \& Brauner, N. (1997). Minimizing the effects of collinearity in polynomial regression. Industrial \& Engineering Chemistry Research, 36(10), 4405-4412.

Shimbov, B., Alguacil, M. \& Suárez, C. (2019). Export structure upgrading and economic growth in the western Balkan countries. Emerging Markets Finance and Trade, 55(10), 2185-2210.

Solow, R. M. (1957). Technical change and the aggregate production function. The Review of Economics and Statistics, 39(3), 312-320. 
Stone, R. (1954). Linear expenditure systems and demand analysis: an application to the pattern of British demand. The Economic Journal, 64(255), 511-527.

Şanlı, D. (2019). The long-run relationship between energy consumption and export sophistication in OECD countries. Ankara Hacı Bayram Veli Üniversitesi İktisadi ve İari Bilimler Fakültesi Dergisi, 21(2), 342-361.

Topallı, N. (2015). Doğrudan yabancı yatırımlar, ekonomik büyüme ve yüksek teknoloji ihracatı arasında bir nedensellik ilişkisi. International Journal of Social Sciences and Education Research, 1(1), 277-285.

Walras, L. (1954). Elements of pure economics or the theory of social wealth (Çev. W. Jaffé). Homewood, IL: Richard D. Irwin (Eserin orjinali 1874 yılında yayınlandi).

Wooldridge, J. M. (2003). Introductory econometrics-A modern approach. Thomson Mason: Ohio.

Yaman, H. ve Sungur, O. (2020). İleri teknoloji ihracatı ve büyüme ilişkisi: OECD ülkelerine yönelik ekonometrik bir analiz. Bolu Abant İzzet Baysal Üniversitesi Sosyal Bilimler Enstitüsü Dergisi, 20(1), 63-80.

Yoo, S. H. (2003). Does information technology contribute to economic growth in developing countries? A cross-country analysis. Applied Economics Letters, 10(11), 679-682.

Yoo, S. H. (2008). High-technology exports and economic output: An empirical investigation. Applied Economics Letters, 15(7), 523-525. 


\section{Ek 1: Veri Setine Dahil Olan Ülkeler}

\begin{tabular}{|l|c|l|c|}
\hline Ülke & Kod & Ülke & Kod \\
\hline Arjantin & 1 & Güney Kore & 26 \\
\hline Avustralya & 2 & Letonya & 27 \\
\hline Avusturya & 3 & Litvanya & 28 \\
\hline Belçika & 4 & Malezya & 29 \\
\hline Brezilya & 5 & Malta & 30 \\
\hline Kanada & 6 & Meksika & 31 \\
\hline Şili & 7 & Hollanda & 32 \\
\hline Çin & 8 & Yeni Zelanda & 33 \\
\hline Hırvatistan & 9 & Norveç & 34 \\
\hline Çek Cumhuriyeti & 10 & Polonya & 35 \\
\hline Danimarka & 11 & Portekiz & 36 \\
\hline Estonya & 12 & Romanya & 37 \\
\hline Finlandiya & 13 & Rusya Federasyonu & 38 \\
\hline Fransa & 14 & Singapur & 39 \\
\hline Almanya & 15 & Slovak Cumhuriyeti & 40 \\
\hline Yunanistan & 16 & Slovenya & 41 \\
\hline Hong Kong & 17 & Güney Afrika & 42 \\
\hline Macaristan & 18 & İspanya & 43 \\
\hline İzlanda & 19 & İsveç & 44 \\
\hline Hindistan & 20 & İsviçre & 45 \\
\hline Endonezya & 21 & Tayland & 46 \\
\hline İlanda & 22 & Türkiye & 47 \\
\hline İsrail & 23 & Birleşik Krallık & 48 \\
\hline İtalya & 24 & A.B.D. & \\
\hline Japonya & 25 & & \\
\hline
\end{tabular}




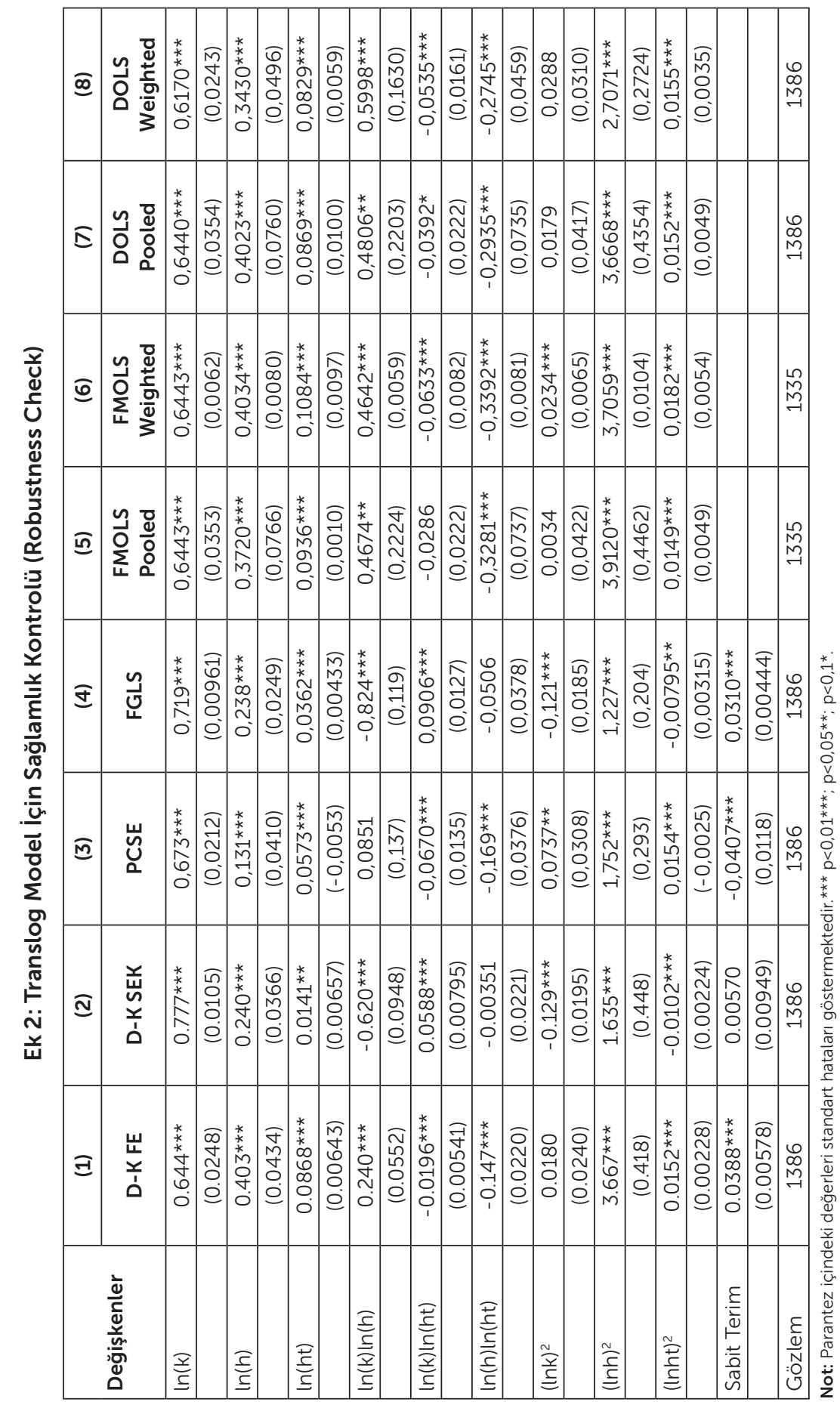

